Article

\title{
Flocculation of Clay Suspensions by Anionic and Cationic Polyelectrolytes: A Systematic Analysis
}

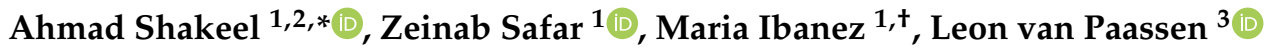 \\ and Claire Chassagne ${ }^{1}$ \\ 1 Department of Hydraulic Engineering, Faculty of Civil Engineering and Geosciences, \\ Delft University of Technology, Stevinweg 1, 2628 CN Delft, The Netherlands; Z.Safar-1@tudelft.nl (Z.S.); \\ Maria.IbanezSanz@anteagroup.com (M.I.); C.Chassagne@tudelft.nl (C.C.) \\ 2 Department of Chemical, Polymer \& Composite Materials Engineering, \\ University of Engineering \& Technology, KSK Campus, Lahore 54890, Pakistan \\ 3 School of Sustainable Engineering and the Built Environment, Arizona State University, 650 E Tyler Mall, \\ Tempe, AZ 85287-3005, USA; leon.vanpaassen@asu.edu \\ * Correspondence: a.shakeel@tudelft.nl \\ † Current address: Antea Group, 2600 Antwerpen, Belgium.
}

Received: 13 October 2020; Accepted: 5 November 2020; Published: 10 November 2020

\begin{abstract}
The characteristics of clayey suspensions, majorly composed of quartz microparticles, in the presence of anionic and cationic polyelectrolytes were investigated using different techniques. A wide range of clay concentrations was used, i.e., from 0.07 to $1000 \mathrm{~g} / \mathrm{L}$ for different experimental techniques, based on the fact that the clay concentration possible to analyze with selected experimental methods was significantly different. The optimum flocculant to clay ratio was defined as the ratio that gives the fastest initial floc growth by static light scattering or fastest initial settling velocity by settling column experiments. In case of anionic polyelectrolyte, it was observed that the optimum flocculant dose depends on the amount of cations present in the system. For suspensions made with demi-water, a lower optimum flocculant dose $(<1 \mathrm{mg} / \mathrm{g})$ than for suspensions prepared in tap water $(2.28 \mathrm{mg} / \mathrm{g})$ was observed. At these lower salinities, the supernatant remained turbid in all the experiments and was, therefore, not a good measure for optimal anionic based flocculation. The equilibrium floc size at a given shear rate was found to be independent on the shear history of the floc and only dependent on the current applied shear. This was confirmed by both light scattering and rheological analysis. In case of cationic polyelectrolyte, the optimum flocculant ratio $(5-6 \mathrm{mg} / \mathrm{g})$ corresponded to the ratio that gives the lowest electrophoretic mobility for each clay concentration and to the ratio that gives the fastest settling velocity for the highest clay concentrations $(12-15 \mathrm{~g} / \mathrm{L})$, where static light scattering measurements were not possible. All investigation techniques, therefore, proved to be good indicators for predicting the optimum flocculant to clay ratio. For the lowest concentrations $(1.75-8.7 \mathrm{~g} / \mathrm{L})$ studied by settling column measurements, the optimum flocculant ratio was observed to increase with decreasing clay concentration, for fixed mixing conditions. The optimum flocculant to clay ratio was not always corresponding to the clearest supernatant and the size of flocs at optimum dosage was dependent on the mixing efficiency. The equilibrium floc size at a given shear rate was found to be dependent on the shear history of the floc and the current applied shear. This was confirmed by both light scattering and rheological analysis.
\end{abstract}

Keywords: clay; anionic and cationic polyelectrolytes; electrophoresis; rheology; settling rate; particle size distribution 


\section{Introduction}

Flocculation has been extensively studied in many fields of science and the studies encompasses detailed modeling of aggregate growth and breakage, in-situ visualization of flocs and laboratory flocculation studies on well-characterized suspensions as a function of organic matter, $\mathrm{pH}$ and salinity [1-5]. In estuarine systems, the changes in physicochemical conditions from the river side to the sea side triggers flocculation and leads to estuarine siltation. This is one of the main causes for the dredging activities in harbors. Organic matter in particular plays a major role in sediment flocculation, because it can easily adhere to the clay particles of the sediment [3].

Flocs can be formed by the addition of flocculating agents, which are classified as: (i) inorganic salts, usually referred to as coagulants, and (ii) organic/carbon-based polymers, defined as flocculants. Organic flocculants are quite common in nature [6,7] and synthetic organic flocculants are widely used in industry for solid-liquid separation [7]. A routinely procedure in industry is for instance the comparison of flocculant performances by studying settling rates. Since the flocculation process is complex, and depends on various parameters like particle and flocculant properties, environmental conditions, i.e., ionic strength, $\mathrm{pH}$, shear stresses, etc. and, therefore, flocculation optimization in industry is often done on an empirical basis. The choice for the "best" flocculant is usually related to factors such as the mineral composition of the particles and the solution chemistry [8]. The efficiency and type of flocculation have been shown to depend on the flocculant structure, molecular weight, charge and dose. For instance in a system where bridging is the predominant flocculation mechanism, a high molecular weight polyelectrolyte will improve the flocculation nearly irrespective of charge [3,9].

Flocculation can also be induced by charge neutralization, i.e., patch mechanism. In that case the polyelectrolyte is usually of low molecular weight. For cationic polyelectrolyte in the presence of negatively charged clays, electrostatic attraction is the main driving mechanism [10]. Polymer bridging in this case leads to stronger and larger aggregates than those formed by coagulation, i.e., aggregation by salt. However, the breakage of these flocs is irreversible and the flocculation performance is very sensitive to the applied mixing conditions [11-13]. As anionic polyelectrolytes are abundant in nature, they have been studied extensively in disciplines like sanitary engineering, i.e., drinking water treatment and biochemistry [14-16]. They are also widely used as flocculating agents in industry, in combination with coagulants. Contrary to the cationic flocculant, which binds easily and irreversibly to negatively charged sediment, the anionic flocculant needs a cationic agent to bind to the sediment [4]. This cationic agent is provided by the dissolved inorganic salts in the system. Most studies are, therefore, done on flocculation in presence of both salt and polyelectrolytes. In natural environments, where particles migrate from fresh water to saline water or vice versa, the flocculation is influenced by the mixing order of the flocculating agents, i.e., flocculants and coagulants.

Even though flocculation has been studied extensively in engineering disciplines like sanitary engineering, process industry, contaminated sediments management, mineral processing, oil drilling and recovery [14-16], the study of flocculation in the frame of natural sediment dynamics is still ongoing $[4,17]$. When flocs are formed in natural environments, they are subjected to different constrains than flocs created in an industrial context. The shear stresses experienced by the flocs are very different, as the in-situ shear rates are usually much lower than those encountered in process plants where slurries are transported in pipes. In-situ shear stresses are, however, strongly spatially and seasonally varying. Moreover the formation of flocs in natural environments is very complex as the availability of primary particles that will compose the flocs and the water composition is both time and space dependent. The study of floc properties in-situ is usually limited to light scattering data, which enables one to determine concentration and particle size distribution as a function of time and space. In order to model the sediment dynamics, it is however important to be able to assess other important properties such as particles settling velocities, aggregation and break-up coefficients. These parameters can be obtained in the laboratory by performing systematic studies as a function of the environmental conditions observed in-situ. 
In the present article, we concentrate on the aggregation, break-up, recovery and settling of flocs obtained in conditions that are as much as possible representative for in-situ conditions. We studied two types of polyelectrolytes with opposite surface charge, i.e., one anionic, the other cationic, as they lead to two different aggregation mechanisms. Well-defined synthetic polyelectrolytes are used as a flocculant so as to provide a reference for further studies where natural polyelectrolytes will be used. Contrary to most studies in mineral processing, oil drilling and recovery, we have chosen to work at an extremely low salinity, which is therefore representative for lake or river-like conditions. The main objective of the current study is to investigate the characteristics of flocculated suspensions using different techniques and also to compare the optimum flocculant dosage obtained by different investigated techniques.

Using four different techniques, we:

1. Investigated the aggregation/break-up dynamics of flocs for a large range of shear rates using static light scattering (SLS) measurements in time, as a function of polyelectrolyte concentrations. Rheological studies were also performed to analyze the structural break-up and recovery of flocs.

2. Investigated the settling of flocs that are formed at extremely low shears (not measureable by SLS) by the column inversion method. Both clay particle concentrations and the relative ratio between clay and flocculant concentration were varied.

3. Investigated the electrokinetic charge of clay particles in the presence of the polyelectrolyte by electrophoresis for different particle concentrations and the relative ratio between clay and flocculant concentrations.

\section{Experimental}

\subsection{Clay}

The clay used in all the experiments, referenced K-10.000, was purchased from the company VE-KA (Werkendam, The Netherlands). The original clay lump had a water content of $35.7 \%$ and a sand content of $21 \%$. The clay was dispersed in demineralized water, the obtained suspension having conductivity less than $0.005 \mathrm{mS} / \mathrm{cm}$. The clay composition was obtained by X-ray powder diffraction (XRPD). Patterns were recorded in Bragg-Brentano geometry in a Bruker D5005 diffractometer equipped with a Huber incident-beam monochromator and Baraun particle size detector (PSD). The samples of about $20 \mathrm{mg}$ were deposited on a Si 510 wafer and were rotated during measurement. Data collection was carried out at room temperature using monochromatic $\mathrm{CuK} \alpha 1$ radiation $(\lambda=0.154056 \mathrm{~nm})$ in the $2 \theta$ region between 5 and $90^{\circ}$, step size 0.038 degrees $2 \theta$. Data evolution was done with the ruker program EVA. The composition of the clay sample is presented in Table 1. The clay was also analyzed with a Phillips XL30 environmental scanning electron microscope (ESEM), from Microlab in the Faculty of Civil Engineering and Geosciences, TU Delft. During the ESEM measurement the sample was under vacuum, with a beam acceleration voltage of $20 \mathrm{kV}$, with the backscattered electrons imaging mode and a spot size of 4 . The magnification is shown Figure 1a. The particle size distribution of the clay was determined by using static light scattering (SLS) technique by means of a Malvern Mastersizer 2000. The results of the particle size distribution of clay are presented in Figure 1b, with a mean diameter $\left(\mathrm{D}_{50}\right)$ of $5.6 \mu \mathrm{m}$.

\subsection{Flocculant}

Anionic and cationic polyacrylamide-based polyelectrolytes, referenced as Zetag 4110 (medium anionic charge with high molecular weight) and Zetag 7587 (high cationic charge with medium molecular weight) respectively, were supplied by BASF Company as a dry powder. These flocculants are principally used for conditioning municipal and industrial effluents prior to mechanical or static solid/liquid separation. The apparent viscosity of anionic and cation flocculant was 1700 and $2200 \mathrm{mPas}$, respectively, at $1 \%$ concentration $(10 \mathrm{~g} / \mathrm{L})$. The dry powder flocculant was suspended in demineralized water to form stock suspensions. The fresh flocculant sample was always used, i.e., less than 3 days old. 
Table 1. The composition of clay analyzed by the X-ray diffraction technique.

\begin{tabular}{cc}
\hline Mineral & Weight $\%$ \\
\hline Quartz & 24.0 \\
Alkali Feldspar & 3.5 \\
Plagioclase & 4.0 \\
Calcite & 9.6 \\
Mg-Calcite & 2.9 \\
Aragonite & 2.7 \\
Dolomite & 0.6 \\
Ankerite & 0.2 \\
Rutile & 0.1 \\
Anatase & 0.1 \\
Gypsum & 0.1 \\
Pyrite & 0.6 \\
Halite & 0.8 \\
Kaolinitic & 3.2 \\
Chloritic & 1.2 \\
2:1 Layer silicates & 46.5 \\
\hline
\end{tabular}
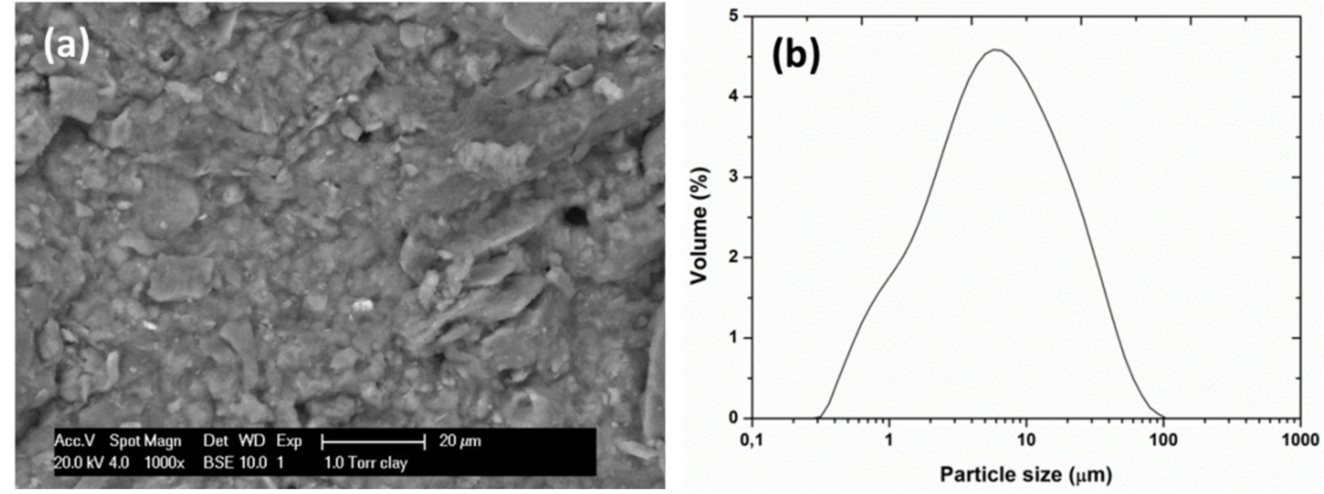

Figure 1. (a) Environmental scanning electron microscope (ESEM) picture and (b) particle size distribution of the clay.

\subsection{Solvent}

The suspensions of clay and flocculant, at the desired concentrations, were prepared with Milli-Q water (conductivity $<0.01 \mathrm{mS} / \mathrm{cm}$ ). Some samples were also prepared by using tap water with a conductivity of $0.5 \mathrm{mS} / \mathrm{cm}$. The relevant tap water specifications are listed in Table 2 . These specifications were obtained from the local drinking water company Evides for the months during which the experiments were performed.

Table 2. Tap water specifications.

\begin{tabular}{ccc}
\hline Parameter & Value & Units \\
\hline $\mathrm{pH}$ & $8.2-8.7$ & - \\
Bicarbonate & $188-225$ & $\mathrm{mg} / \mathrm{L}$ \\
Sulphate & $24-30$ & $\mathrm{mg} / \mathrm{L}$ \\
Sodium & $51-59$ & $\mathrm{mg} / \mathrm{L}$ \\
Calcium & $45-49$ & $\mathrm{mg} / \mathrm{L}$ \\
Magnesium & $8.2-8.4$ & $\mathrm{mg} / \mathrm{L}$ \\
Chloride & $48.6-49.1$ & $\mathrm{mg} / \mathrm{L}$ \\
\hline
\end{tabular}




\subsection{Static Light Scattering Experiments}

\subsubsection{Particle (Floc) Size Distribution}

The particle size distribution (PSD) of the samples was measured by the static light scattering (SLS) technique by means of a Malvern Mastersizer 2000. The software evaluates the volume-based particle size distribution using Mie theory of light scattering, by assuming that the particles are spherical [18]. This theory, therefore, does not take into account the irregularity in the shape of flocs. A clay suspension of $0.7 \mathrm{~g} / \mathrm{L}$ was used for all the particle (floc) size measurements. The clay concentration of $0.7 \mathrm{~g} / \mathrm{L}$ was the highest concentration at which detection was possible by the laser of SLS equipment, i.e., obscuration of $30 \%$. The flocculation experiments were performed in a JLT6 jar test set-up provided by VELP Scientifica, Italy. The dimensions of the jar were: inner diameter of $95 \mathrm{~mm}$ with the height of $110 \mathrm{~mm}$. The suspension was stirred using a single rectangular paddle. The paddle was $25 \mathrm{~mm}$ high and $75 \mathrm{~mm}$ in diameter. It was placed $10 \mathrm{~mm}$ above the bottom of the jar in the suspension. The suspensions were pumped through the Malvern Mastersizer 2000, with the help of a peristaltic pump, from the mixing-jar to the Mastersizer and then back to the mixing-jar (see Figure 2). This set-up allowed us to control independently the speed of the pump and the paddle of the mixing-jar. The internal diameter of the connecting tubes was $5 \mathrm{~mm}$ and the total length was the shortest possible allowed by the set-up, i.e., $2400 \mathrm{~mm}$ from the jar and back to the jar). The average shear rate in the jar was the lowest possible shear rate, i.e., $75 \mathrm{rpm}$, which corresponded to less than $50 \mathrm{~s}^{-1}$ [19] to prevent the settling of particles in the jar. The discharge for pumping the sample into the Mastersizer was $1.92 \mathrm{~mL} / \mathrm{s}$, the lowest possible to prevent the settling of particles in the pipes. Using these low shear rates, we expected to minimize the floc break-up in the jar and connecting tubes. With this set-up, it was possible to record a full particle size distribution (PSD) after every $30 \mathrm{~s}$.

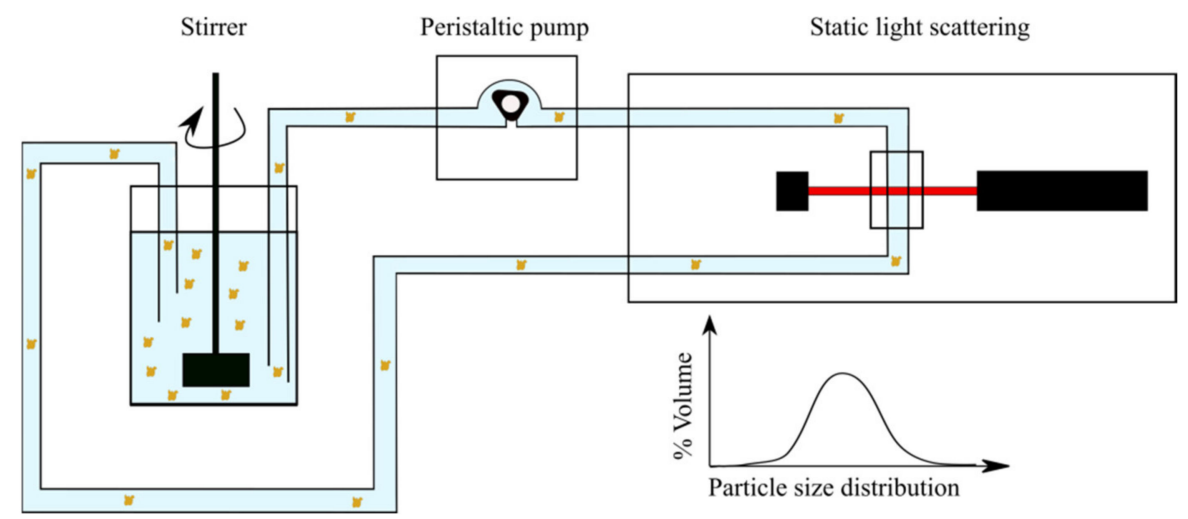

Figure 2. Sketch of the experimental setup.

\subsubsection{Shear Stress Experiments}

The same set-up, as detailed above for the jar test, was used during the shear stress experiments, but the discharge rate from the pump was varied. For each step, we waited until the mean floc size reached a steady state value. The shear rate in the connecting tubes for each discharge rate was calculated by using the following relation:

$$
\dot{\gamma}=\frac{4 Q}{\pi r^{3}}
$$

where $Q$ is the discharge rate and $r$ is the radius of the connecting tube $(2.5 \mathrm{~mm})$. Preliminary experiments, done by varying the shear stress in the jar and connecting tube, confirmed that the change in the size of flocs mainly occurred in the connecting tubes. The discharge rate was increased in four steps from $1.92\left(150 \mathrm{~s}^{-1}\right)$ to $15 \mathrm{~mL} / \mathrm{s}\left(1220 \mathrm{~s}^{-1}\right)$ and then decreased again, to investigate if the flocculation process was reversible. The floc size was recorded using the SLS technique as the flocs entered the 
measurement chamber connected to the tubes. The clay concentration was always $0.7 \mathrm{~g} / \mathrm{L}$ in shear stress experiments.

\subsection{Settling Column Experiments}

The settling experiments were carried out in $500 \mathrm{~mL}$ glass columns with a diameter of $4.5 \mathrm{~cm}$ and length of about $27 \mathrm{~cm}$. These experiments were performed for different clay concentrations, ranging from 1.75 to $15 \mathrm{~g} / \mathrm{L}$. The flocculant was added to each clay concentration in different doses (mg/L), to determine the optimum flocculant dose per clay concentration $(\mathrm{mg} / \mathrm{g})$. After adding the flocculant to the clay suspension, the settling column was inverted 10 times by hand (this protocol we termed as "column inversion standard procedure"). Immediately after the end of inversions, when the column was placed on a table, pictures were taken after every $5 \mathrm{~s}$ during the whole time of settling until the consolidation phase was reached. A fresh sample was prepared for each experiment. The settling rate $(\mathrm{mm} / \mathrm{s})$ was determined from the initial slope of the interface versus time. The shear rate using this method was estimated by the following equation:

$$
\dot{\gamma}=\frac{d u}{d z} \simeq \frac{\sqrt{2 g \Delta h}}{R}
$$

where $g$ is the gravity constant, $R$ is the radius of the column $(2.25 \mathrm{~cm})$ and $\Delta h$ is the distance between the liquid/air interface of the suspension and the top of the column. This gave an estimated shear rate of $60 \mathrm{~s}^{-1}$ for all the measurements.

\subsection{Electrophoretic Mobility and $\zeta-P o t e n t i a l$}

The electrophoretic mobility of the suspensions was measured using a Malvern ZetaNano device. The mobilities were expressed in zeta potential units $(\zeta)$ using the Smoluchowski formula [20], given as follows:

$$
\zeta=\frac{\eta \mu}{\varepsilon}
$$

where $\mu$ is electrophoretic mobility of the particle, $\eta$ is the viscosity of the suspending liquid and $\varepsilon$ is the dielectric constant of the suspending medium. The applied voltage during the measurements was $50 \mathrm{~V}$, which was found to be an optimal value for these types of measurements [21]. The electrokinetic charge or zeta potential of a particle is minimum, i.e., close to zero when the interaction energy between two particles is minimal. The point of zero (electrokinetic) charge therefore indicates the ratio between clay and flocculant concentrations at which flocculation should be optimal for well-mixed conditions. The zeta potential was measured at different clay concentrations and as a function of flocculant dose. Prior to each measurement, the flocculant was added to the clay suspension. The suspension was then gently stirred for $10 \mathrm{~s}$ in a $50 \mathrm{~mL}$ beaker and injected immediately in the measuring cell. The zeta potential of the clay, suspended in demi water, was $-17 \pm 2 \mathrm{mV}$ at $\mathrm{pH} 8$.

\subsection{Rheological Measurements}

The rheological properties of flocculated clay suspensions were analyzed using a HAAKE MARS I rheometer (Thermo Scientific, Germany) with vane-in-cup geometry. Structural recovery test [22] was performed to effectively break the flocs and to analyze the structural recovery after shearing action. The structural recovery test was started with a waiting time of 100 s, i.e., oscillatory time sweep within the linear viscoelastic (LVE) regime, after reaching the measurement position, to eliminate the disturbances created by the geometry and also to estimate the storage modulus before the structural breakup. The steady shearing step was then performed at a shear rate of $100 \mathrm{~s}^{-1}$ for the duration of $500 \mathrm{~s}$. After that, structural recovery was carried out by performing oscillatory time sweep experiments within linear viscoelastic regime at the frequency of $1 \mathrm{~Hz}$ for $500 \mathrm{~s}$. During each experiment, the temperature was maintained at $20^{\circ} \mathrm{C}$ using a Peltier controller system. The rheological experiments were performed at different concentrations of clay ranging from 430 to $670 \mathrm{~g} / \mathrm{L}$, i.e., from 30 to $40 \mathrm{wt} \%$, which were 
high enough to have interactions between the articles, in order to assess the rheological fingerprint of the suspensions. The flocculant amount was also varied to estimate the effect of flocculant dosage on the structural recovery of flocs.

\section{Results and Discussion}

\subsection{Static Light Scattering (SLS) Measurements}

\subsubsection{Particle Size Evolution as a Function of Time}

\section{Anionic Flocculant}

The flocculation behavior of the clay with anionic and cationic flocculants was studied by measuring the particle size distribution (PSD) as a function of time by static light scattering (SLS). For each polyelectrolyte concentration, a new fresh sample was prepared, i.e., polyelectrolyte was not added to a previously flocculated sample. The flocculant was added in all the experiments at a time $t=0 \mathrm{~s}$. The particle size distribution of pure clay before the addition of flocculant is represented as "Clay". The changes in the particle size distribution as a function of time for flocculated suspensions in the presence of anionic flocculant below, at and above the optimal dosage are shown in Figure 3a-c. The optimal dose of flocculant was evaluated from these experiments and was defined as the dose for which the initial slope $\mathrm{dD}_{50} / \mathrm{dt}$ was the highest. This definition is in accordance with the definition found in the literature [23].
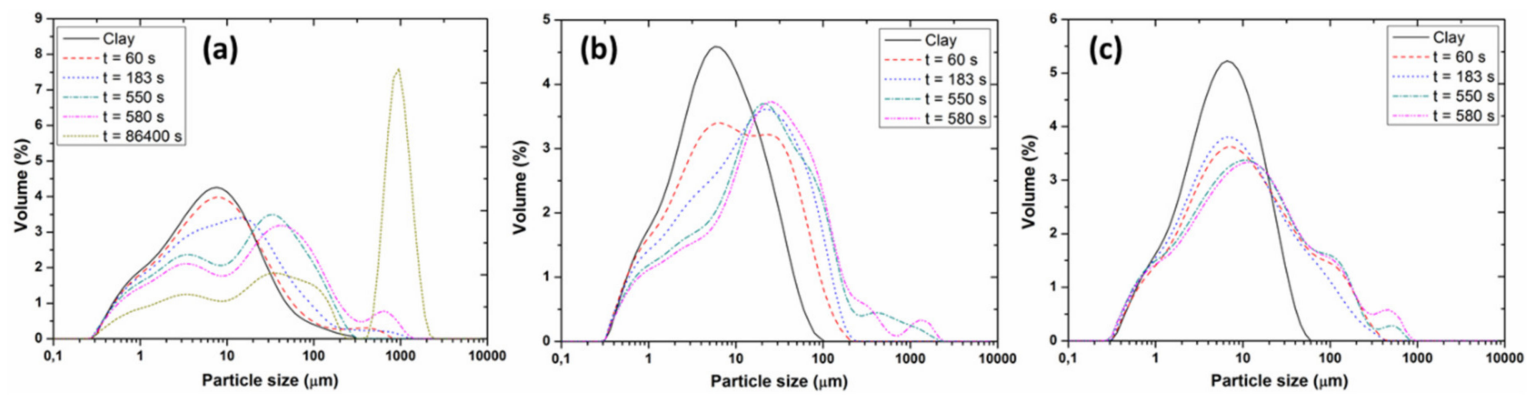

Figure 3. Particle size distribution for $0.7 \mathrm{~g} / \mathrm{L}$ clay concentration with (a) $0.05 \mathrm{mg} / \mathrm{g}$, (b) $0.25 \mathrm{mg} / \mathrm{g}$ and (c) $2.5 \mathrm{mg} / \mathrm{g}$ anionic flocculant. "Clay" represents the particle size distribution (PSD) of pure clay before addition of flocculant and $\mathrm{t}=0 \mathrm{~s}$ corresponds to the time when the flocculant was added.

Contrary to the flocculation with cationic flocculant (discussed below), it was noted that a substantial amount of small particles $(<10 \mu \mathrm{m})$ remained in suspension over time, indicating that these small particles were not taken up by the larger flocs (see Figure 3a-c). As a consequence, a bimodal (or multimodal) distribution over time was observed. This was also reflected by the higher turbidity of suspensions having anionic flocculant, even at optimal dosage. The largest particle size was $<20 \mu \mathrm{m}$ for all the experiments with short experimental times. Sample in Figure 3a was continuously stirred in the jar and remeasured after $24 \mathrm{~h}(86,400 \mathrm{~s})$. Some particles were grown until $1 \mathrm{~mm}$, but 55\% (in volume) was still below $200 \mu \mathrm{m}$. The formation of large particles was attributed to the fact that the sample was only stirred in the jar, i.e., not pumped through the measurement chamber, and therefore the particle growth was not limited by the size of the connecting tubes and the shear within.

The estimation of the highest $\mathrm{dD}_{50} / \mathrm{dt}$ slope was difficult, see Figure $4 \mathrm{a}$, and, due to the bimodal or even multimodal nature of the PSD, the use of the $\mathrm{D}_{50}$ as the representative floc size, besides leading to erratic values as a function of time, is questionable. From the initial slopes of the $\mathrm{D}_{50}$ curves as a function of time, it was estimated that the fastest initial growth and, therefore, the optimal flocculant dose was below $0.5 \mathrm{mg} / \mathrm{g}$, flocculant to the clay ratio. It can be seen from Figure $4 \mathrm{~b}$ that the floc size decreased by increasing the flocculant dosage higher than the optimal flocculant dosage. At large times, however there was an overall trend between floc size and flocculant dosage, i.e., the $\mathrm{D}_{50}$ value 
was decreasing with flocculant dosage (see the data for $t=600 \mathrm{~s}$ in Figure $4 \mathrm{~b}$ ). Note that the initial growth rate for all the dosages below $0.5 \mathrm{mg} / \mathrm{g}$ are roughly the same, as can be seen in Figure $4 \mathrm{c}$.
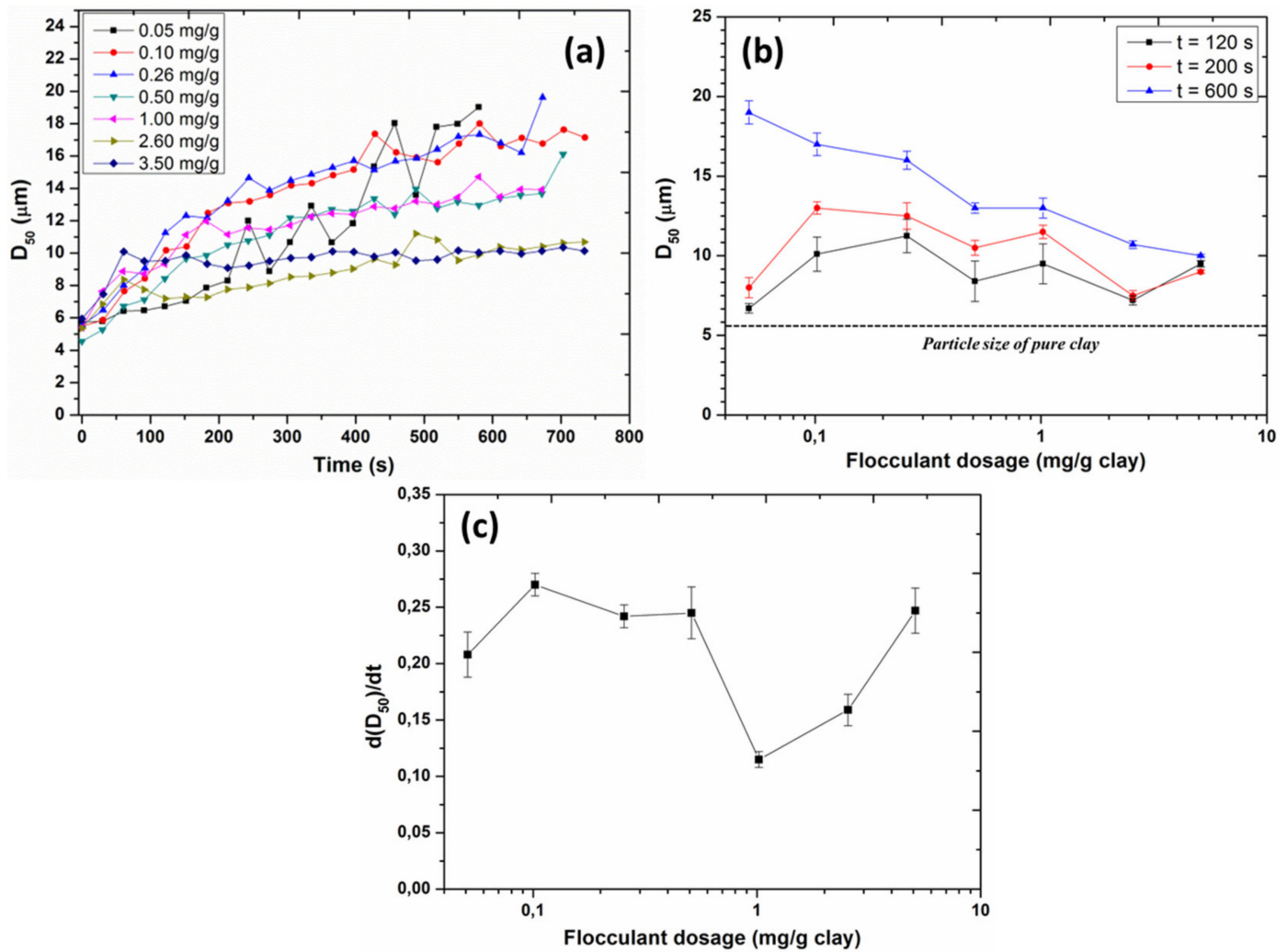

Figure 4. (a) Evolution of $D_{50}$ as a function of time for clay concentration of $0.7 \mathrm{~g} / \mathrm{L}$ with different concentrations of anionic flocculant, (b) evolution of $\mathrm{D}_{50}$ as a function of flocculant to the clay ratio $\left(\mathrm{mg} / \mathrm{g}\right.$ ), and (c) $\mathrm{dD}_{50} / \mathrm{dt}$ as a function of flocculant to the clay ratio $(\mathrm{mg} / \mathrm{g})$. Bars represent standard deviation.

The aggregation can be done through the neutral parts of the polyacrylamide through hydrogen bonding. Mpofu et al. [24,25] found, for example, that the hydrogen bonding between the silanol and aluminol at their smectite clay particle surface and the amide groups of the polymer, was the reason of their observed flocculation.

Several authors have suggested a "cationic bridging" mechanism to explain the binding of negatively charged clay with the negatively charged polyelectrolyte $[4,10,26,27]$. Following this mechanism, divalent cations are required to make a link between the negatively charged clay and the negatively charged polymer. At the same time, in the presence of salt, the Coulombic repulsions between particles and flocculant reduce dramatically as compared to a (nearly) salt-free situation, favoring van der Waals attraction. As the clay suspension we used is not dialyzed, it is expected that some cations (and anions) are part of the solvent, and, therefore, that part of the flocculation mechanism may be attributed to cation bridging.

At low flocculant dosage, where we observed larger flocs at long times (Figure 4b) two effects might play a role: the radius of gyration of a polyelectrolyte at low polyelectrolyte concentration is higher, leading to a better capture efficiency. At the same time the flocculation efficiency by cation bridging or hydrogen bonding of a clay particle by a polyanion is higher at a low polyelectrolyte dosage than at higher polyelectrolyte dosage, where interparticular repulsion, i.e., polyelectrolyte-polyelectrolyte and polyelectrolyte-clay is a limiting factor. 


\section{Cationic Flocculant}

The particle size distribution as a function of time for cationic flocculated suspensions, below $(0.5 \mathrm{mg} / \mathrm{g})$ and near the optimal dosage $(2.5 \mathrm{mg} / \mathrm{g})$, are shown in Figure $5 \mathrm{a}, \mathrm{b}$. During flocculation, the amount of small particles $(<10 \mu \mathrm{m})$ was considerably reduced, indicating their binding to the larger flocs. This was also reflected by the clarity of suspensions where large flocs were observed in clear water. The size of the largest flocs, obtained with $2.5 \mathrm{mg} / \mathrm{g}$ flocculant dosage, became smaller in time (Figure $5 b$ ). This phenomenon was also observed for higher flocculant doses, as can be seen in Figure 6a. This was attributed to the reconformation of flocs due to the shearing action and was confirmed by a $15 \mathrm{~min}$ visual observation of a stirred sample at optimal flocculant dose and $8.7 \mathrm{~g} / \mathrm{L}$ clay content. In time, the large loose flocs reconformed into dense spherical balls.
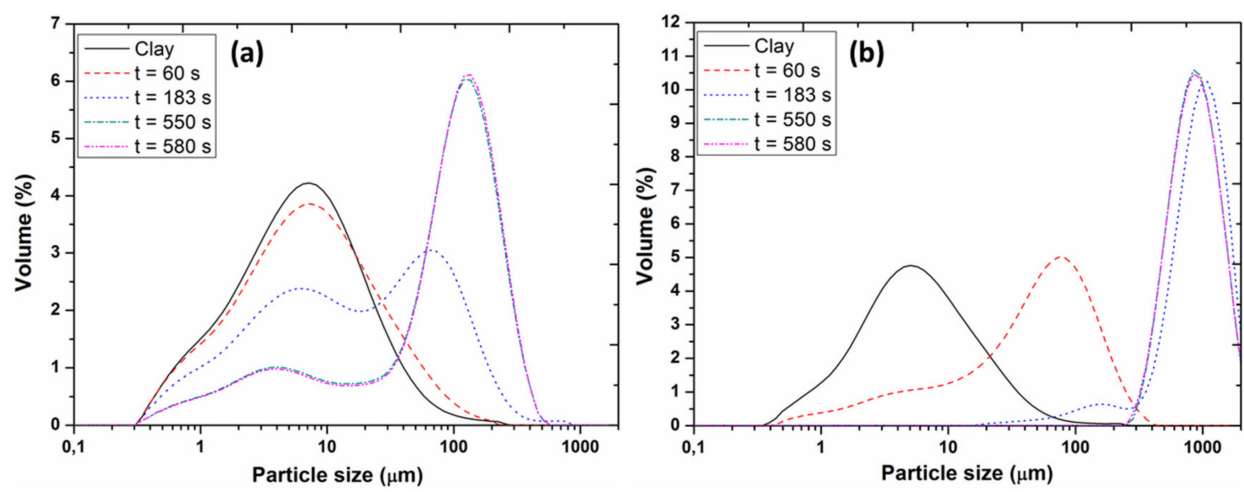

Figure 5. Particle size distribution for $0.7 \mathrm{~g} / \mathrm{L}$ clay concentration with (a) $0.5 \mathrm{mg} / \mathrm{g}$ and (b) $2.5 \mathrm{mg} / \mathrm{g}$ cationic flocculant. "Clay" represents the PSD of pure clay before addition of flocculant and $\mathrm{t}=0 \mathrm{~s}$ corresponds to the time when the flocculant was added.
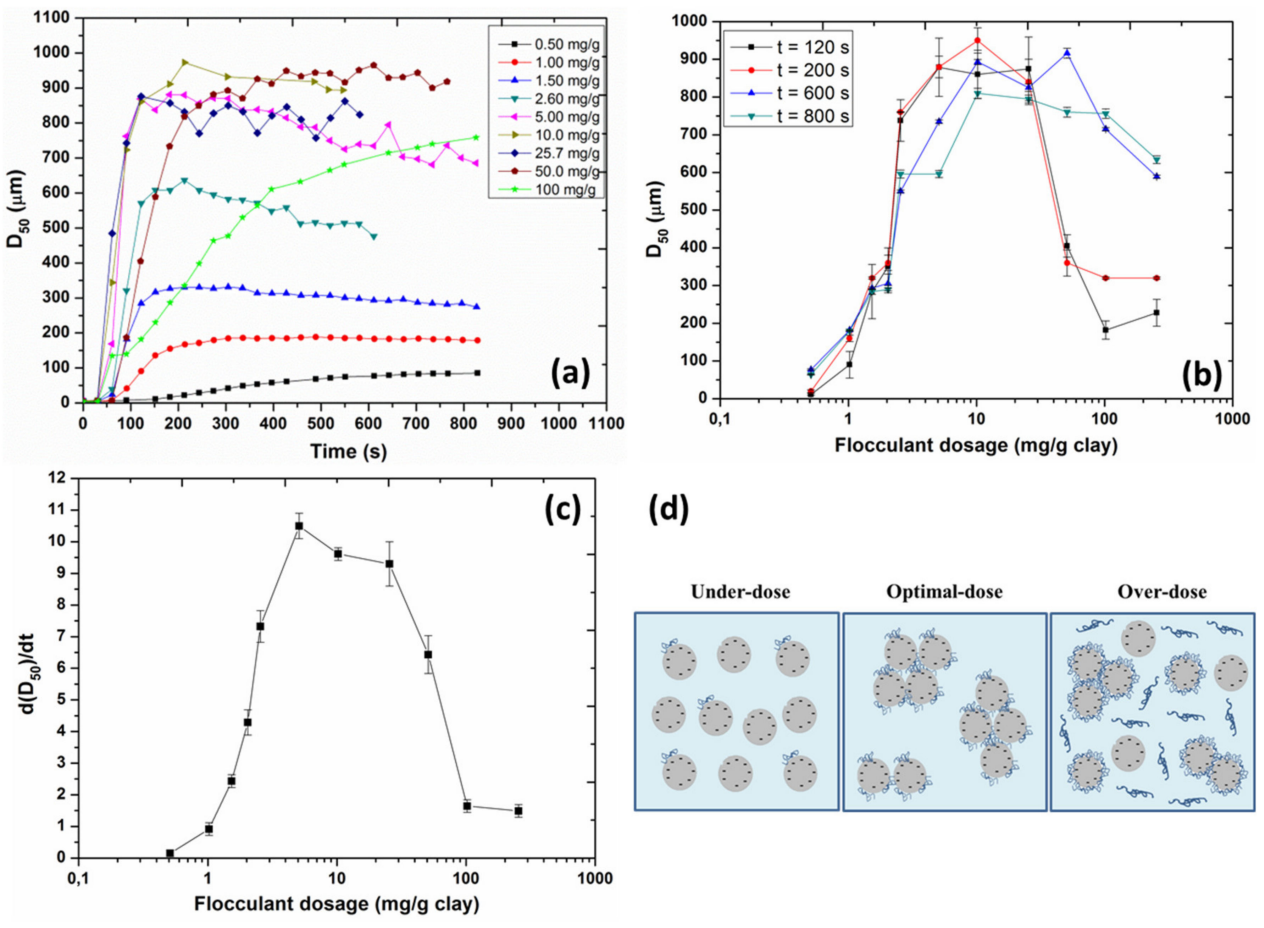

(d)

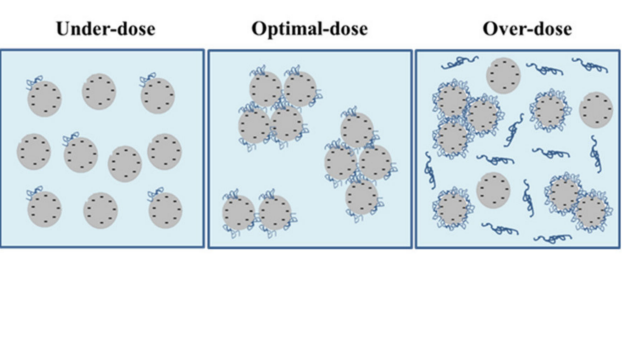

Figure 6. (a) Evolution of $\mathrm{D}_{50}$ as a function of time for clay concentration of $0.7 \mathrm{~g} / \mathrm{L}$ with different concentrations of cationic flocculant, (b) evolution of $\mathrm{D}_{50}$ as a function of flocculant to clay ratio $(\mathrm{mg} / \mathrm{g}),(\mathbf{c}) \mathrm{dD}_{50} / \mathrm{dt}$ as a function of flocculant to clay ratio $(\mathrm{mg} / \mathrm{g})$ and $(\mathbf{d})$ schematic representation of flocculation of clay at under-dose, optimal-dose and over-dose of flocculant. Grey circles represent the clay particles and blue lines represent the flocculant. Bars represent standard deviation. 
In Figure 6a, typical $\mathrm{D}_{50}$ as a function of time for a large dosage range (covering under-dose, optimal-dose and over-dose flocculant) are presented. The steepest initial slopes $\left(\mathrm{dD}_{50} / \mathrm{dt}\right)$ were found for $\mathrm{t}<200 \mathrm{~s}$. Figure $6 \mathrm{~b}, \mathrm{c}$ show that both $\mathrm{D}_{50}$ and $\mathrm{dD}_{50} / \mathrm{dt}$ reached a maximum value at about $5 \mathrm{mg} / \mathrm{g}$ flocculant dose. This indicated that at optimal flocculant dose $(5 \mathrm{mg} / \mathrm{g})$, the flocs were largest along with having the fastest growth rate. For flocculant amounts higher than the optimum dosage, the time to reach the largest $D_{50}\left(D_{50 \max }\right)$ increased, as can be seen in Figure $6 a, b$. This was attributed to the fact that there was a substantial amount of flocculant in suspension, i.e., not bounded to the clay, and therefore, the flocculation was inhibited by the electrostatic repulsion between the polyelectrolyte tails of the flocculated clay particles and the free polyelectrolytes in solution (see Figure 6d).

\subsubsection{Reversibility Upon Shear}

\section{Anionic Flocculant}

The influence of shear rate on the floc size and the reversibility upon shear was investigated by the method detailed in the experimental section and the results for suspensions flocculated with a polyanion are presented in Figure 7.

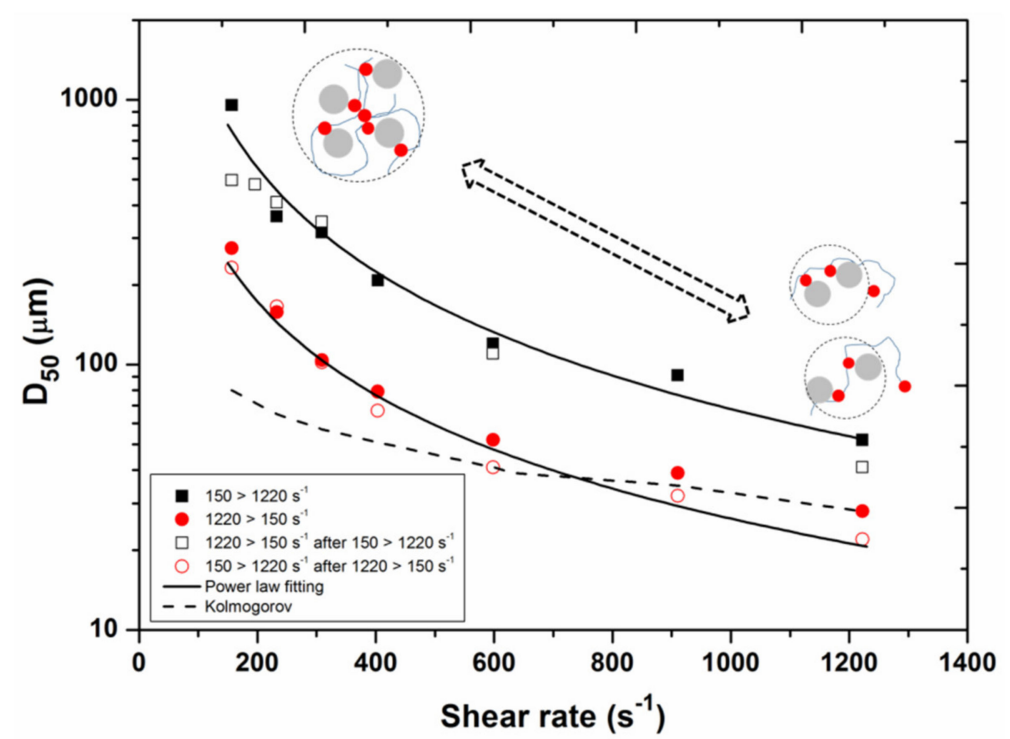

Figure 7. Variation of equilibrium (steady state) floc size $\left(D_{50}\right)$ as a function of shear rate for clay concentration of $0.7 \mathrm{~g} / \mathrm{L}$ with $0.5 \mathrm{mg} / \mathrm{g}$ of the anionic flocculant. The red circles represent flocs initially grown at a higher shear rate and the black squares denote flocs initially grown at a lower shear rate. The filled symbols indicate flocs created at the onset of experiments whereas the open symbols indicate flocs already experienced shearing action. The dashed line represents the Kolmogorov length scale.

It was estimated that the Reynolds number was larger than 2000 for shear rates higher than $500 \mathrm{~s}^{-1}$ implying that for lower shear rates the regime was in good approximation of laminar flow. It can be observed from Figure 7 that:

- $\quad$ Flocs created at a lower shear rate were large, i.e., about $1 \mathrm{~mm}$ (filled squares in Figure 7) and their dependence on the shear rate was nearly completely reversible, as indicated by the empty squares in Figure 7. Only for the lowest shear rates the flocs regrew to half of their original size (i.e., about $500 \mu \mathrm{m}$ ).

- $\quad$ Flocs created at higher shear were always smaller (filled circles in Figure 7) than the flocs created at lower shear and a complete reversibility in floc size as a function of shear rate was observed (empty circles in Figure 7). 
The dependence of floc size upon shear rate can be given in terms of the following empirical relation [28]:

$$
d=C \times(\dot{\gamma})^{-\alpha}
$$

where $d$ is the floc diameter, $\dot{\gamma}$ is the shear rate and $C$ and $\alpha$ are the empirical parameters. Usually the exponent $\alpha$ is found experimentally to be close to 0.5 at a higher shear rate, which is to be related to the Kolmogorov microscale L, i.e.,:

$$
L=(v / \dot{\gamma})^{-1 / 2}
$$

where $v$ is the kinematic viscosity of the fluid. Flocs created at a high shear rate follow the Kolmogorov microscale in the turbulent regime, i.e., for shear rates larger than $500 \mathrm{~s}^{-1}$. The values of $\alpha$, obtained by fitting the data (solid lines in Figure 7) were found to be 1.31 and 1.13 for $150>1220 \mathrm{~s}^{-1}$ and $1220>150 \mathrm{~s}^{-1}$ datasets respectively, which are close to the values reported in the literature [28].

The difference in floc sizes created at higher or lower shear rates was attributed to the change in conformation of the polyelectrolyte. At a lower shear rate, the polyelectrolyte can significantly extend into the solution and the flocs created at low shear were, therefore, large and open. When the shear rate was increased, the polyelectrolyte detached from the clay without being broken, as the cationic links and the hydrogen bonding are weak forces. The flocs also reconformed, i.e., became denser as their tails and loops collapsed onto their surfaces. By decreasing the shear rate then, the flocs could open-up and the detached parts could regrow. However, the regrowth was not completely reversible due to some permanent reconformation of the polyelectrolyte at high shear.

On the other hand, the aggregation/flocculation was totally different for the flocs created at a higher shear rate. At higher shear, the entanglement of the polyelectrolyte chains was pronounced at the onset of flocculation and the flocs were, therefore, denser. This resulted in the fact that flocs created at high shear were smaller than flocs created at low shear rate. By reducing the shearing action, the flocs were able to grow larger, due to cationic bridging and hydrogen bonding and also due to the fact that parts of the loops and tails of polyelectrolyte can extend better in the solution.

\section{Cationic Flocculant}

The floc size reversibility as a function of shear rate was also examined for cationic flocculated suspensions and the results are shown in Figure 8. It was found that:

- Flocs created at a low shear rate at or above optimal flocculant dose (see $10 \mathrm{mg} / \mathrm{g}$ flocculant dosage) were large, i.e., about $1 \mathrm{~mm}$ (filled squares in Figure 8) and the floc size dependence on shear rate was not at all reversible, as indicated by the empty squares in Figure 8.

- At underdose flocculant $(0.1 \mathrm{mg} / \mathrm{g})$ the flocs created were small and close to the Kolmogorov length. The flocs regrew to their initial steady-state value upon a decrease in shear, except at the lowest measured shear, where they regrew to a size of 86 microns instead of a size of 145 microns.

Only part of the broken flocs was observed to subsequently regrow at high flocculant dosage, as seen in Figure 8a. As during the regrowth phase, the PSD was bimodal (Figure $8 b$ ), the $\mathrm{D}_{50}$ value was not an appropriate parameter for the mean floc size. Therefore, one of the consequences was the existence of a "hump" around $700 \mathrm{~s}^{-1}$ in the $\mathrm{D}_{50}$ value as a function of decreasing shear rate (see open circles in Figure 8a). This implies that Equation (5) cannot be applied for the regrowth phase.

In case of salt-induced flocs, a complete reversal of floc size by the increasing and decreasing shear rate was observed in the literature, which then followed the Kolmogorov microscale as a function of shear [5,29]. Polycation-induced aggregates are much stronger, which implies that during the growth phase, the elastic properties of the polyelectrolyte prevent the flocs of being disrupted by the low shear stresses. Their size was, therefore, larger than the Kolmogorov microscale. At higher shear stresses, however, the flocs were broken and a collection of microflocs was formed. These microflocs were not (or only poorly) reflocculated upon a decrease in shear, due to the fact that their steric repulsion was not compensated by the addition of new flocculant or coagulant [30]. 

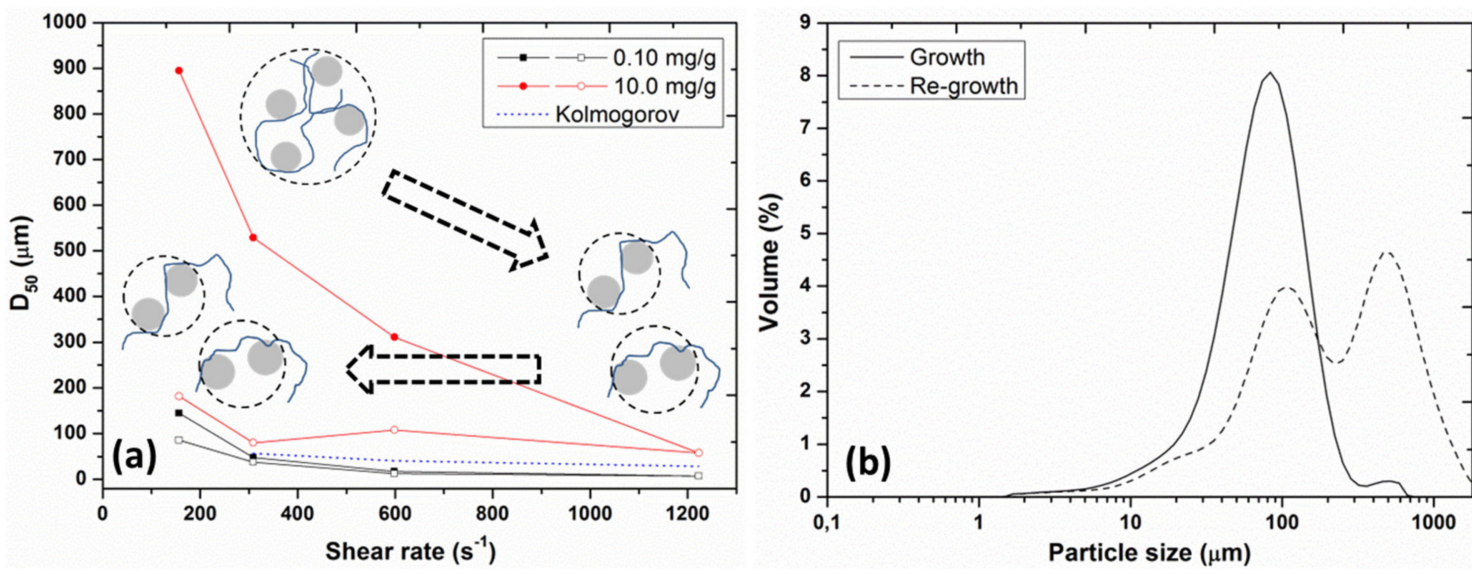

Figure 8. (a) Variation of equilibrium (steady state) floc size $\left(D_{50}\right)$ as a function of shear rate for clay concentration of $0.7 \mathrm{~g} / \mathrm{L}$ with different amounts of cationic flocculant. The filled symbols indicate the flocs created at the onset of experiments whereas the open symbols indicate the flocs already experienced shearing action. The dashed line presents the Kolmogorov length scale, (b) particle size distribution for $10 \mathrm{mg} / \mathrm{g}$ flocculant to clay ratio at a steady state $(\mathrm{t}=9000 \mathrm{~s})$ for $\dot{\gamma}=600 \mathrm{~s}^{-1}$ during the growth phase and for $\dot{\gamma}=300 \mathrm{~s}^{-1}(\mathrm{t}=3000 \mathrm{~s})$ during the regrowth phase.

\subsection{Settling Column Measurements}

\subsubsection{Anionic Flocculant}

To study the settling behavior of flocculated suspensions, experiments were done for clay concentrations ranging between 1.75 and $15 \mathrm{~g} / \mathrm{L}$. A series of experiments with varying flocculant dose were performed, following the column inversion standard procedure, from which the optimum flocculant dose could be estimated by determining the initial fastest settling rate. An example of the settling behavior of clay suspension ( $7 \mathrm{~g} / \mathrm{L}$ clay) in the presence of different doses of anionic polyelectrolyte is given in Figure 9. The optimal flocculant dose, for this clay concentration, was found to be $2.28 \mathrm{mg} / \mathrm{g}$. Below the optimal flocculant dose, a single settling rate was observed whereas delayed settling appeared after $40 \mathrm{~s}$ ("second rate" in Figure 9a) above the optimal flocculant dose. Similar delayed settling rates were also reported in the literature for the settling of activated sludge in the presence of anionic polyelectrolytes [31,32]. These authors associated this change in the settling rate, referred to as the "speed up" process, with the flocculation process occurring during the settling. Some aggregation was also visually observed in our settling columns for these flocculant doses during settling, leading to complex hydrodynamic patterns. All initial settling rates ("initial rate" in Figure 9a) displayed an increasing trend with increasing flocculant dose below the optimum level while further increase in the flocculant amount beyond the optimum dosage caused a decrease in the initial settling rate.

The initial settling rate as a function of flocculant dosage for different clay concentrations is presented in Figure $9 \mathrm{~b}$. The initial settling rate increased for all the clay concentrations with increasing flocculant dosage until about $2.28 \mathrm{mg} / \mathrm{g}$, where the highest initial settling rate was observed. This settling rate corresponded to the optimum flocculant dose and also to the lowest turbidity of the supernatant, even though the suspensions remained quite turbid. 

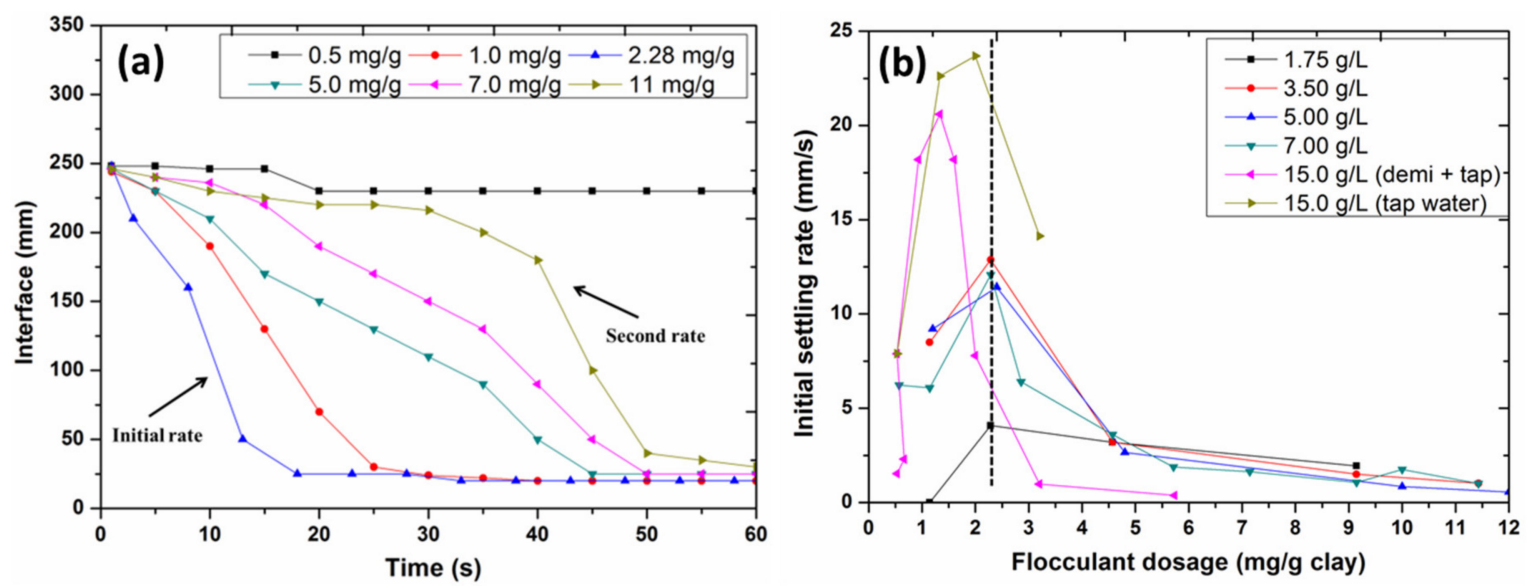

Figure 9. (a) Clay-water interface as a function of time for $7 \mathrm{~g} / \mathrm{L}$ clay suspensions in the presence of anionic polyelectrolyte for various flocculant to clay ratios $(\mathrm{mg} / \mathrm{g})$ and $(\mathbf{b})$ initial settling rate (initial slope) as a function of flocculant to clay ratio $(\mathrm{mg} / \mathrm{g})$ for different clay suspensions in the presence of the anionic polyelectrolyte.

In the first set of experiments, clay stock solution prepared in demineralized water, flocculant and tap water was mixed to obtain the required clay concentration. From a simple linear interpolation, assuming that the amount of cations available for each experiment was proportional to the added tap water volume $\mathrm{V}$, one can estimate the optimal flocculant to the clay ratio from the following expression:

$$
C_{o p t}=\frac{V}{V_{0}} C_{o p t}^{1.75}
$$

where $1.75 \mathrm{~g} / \mathrm{L}$ sample was used as a reference, for which $C_{o p t}^{1.75}=2.28 \mathrm{mg} / \mathrm{g}$ and $V=V_{0}=233 \mathrm{~mL}$. The optimal doses for samples $1.75-7 \mathrm{~g} / \mathrm{L}$ were then found to be about $1.9-2.18 \mathrm{mg} / \mathrm{g}$, as most of the water in the column was then tap water. For the $15 \mathrm{~g} / \mathrm{L}$ sample, on the other hand, a significant amount of demineralized water is present in the column (added tap water $V=133 \mathrm{~mL}$ ), which is reflected in the behavior of the sample labeled (demi + tap) in Figure $9 \mathrm{~b}$, where we found $C_{o p t}=1.3 \mathrm{mg} / \mathrm{g}$. In a second set of experiments, a new clay stock suspension was prepared in tap water instead of demineralized water and the results for the $15 \mathrm{~g} / \mathrm{L}$ sample were labeled (tap water) in Figure 9b. As expected, the value of $C_{\text {opt }}$ was then quite close to $2.28 \mathrm{mg} / \mathrm{g}$.

It was observed that the settling rate was significantly larger for the $15 \mathrm{~g} / \mathrm{L}$ samples compared to the other clay concentrations for a given flocculant to clay ratio. This was due to the fact that for these high clay concentrations, the flocs were in contact with each other and the suspension had a gel-like structure. Therefore, the initial settling rate was not the representative of free settling of the flocs but the collapse of the structure under its own weight. Due to the displacement of large volumes, the water/structure interface settled down much faster than the free settling case. The lowest settling rate observed for the $1.75 \mathrm{~g} / \mathrm{L}$ clay concentration was due to the lack of collision frequency at the timescale of the experiment, i.e., the standard inversion procedure lasts for about $30 \mathrm{~s}$. The clay suspension remained very turbid and it was difficult to find the supernatant/settling clay interface.

\subsubsection{Cationic Flocculant}

Settling experiments were performed for cationic flocculated suspensions with varying flocculant dose and clay concentrations. The clay-water interface as a function of time for $8.7 \mathrm{~g} / \mathrm{L}$ clay concentration and different flocculant concentrations is plotted in Figure 10a. Figure 10b shows the settling rate as a function of flocculant dosage for different clay concentrations. The optimum flocculant dosage, for cationic polyelectrolyte, was found to be about $5-15 \mathrm{mg} / \mathrm{g}$ depending upon the clay concentration. As for the anionic polyelectrolyte, the settling rate decreased with increasing cationic flocculant dose 
beyond the optimal dosage. This decrease in settling rate was in agreement with other studies $[33,34]$. For instance Wen et al. [35] observed that the flocs obtained with optimum dose of cationic polyelectrolyte in clay sludge had the same size but were denser than the flocs obtained at higher dosage.
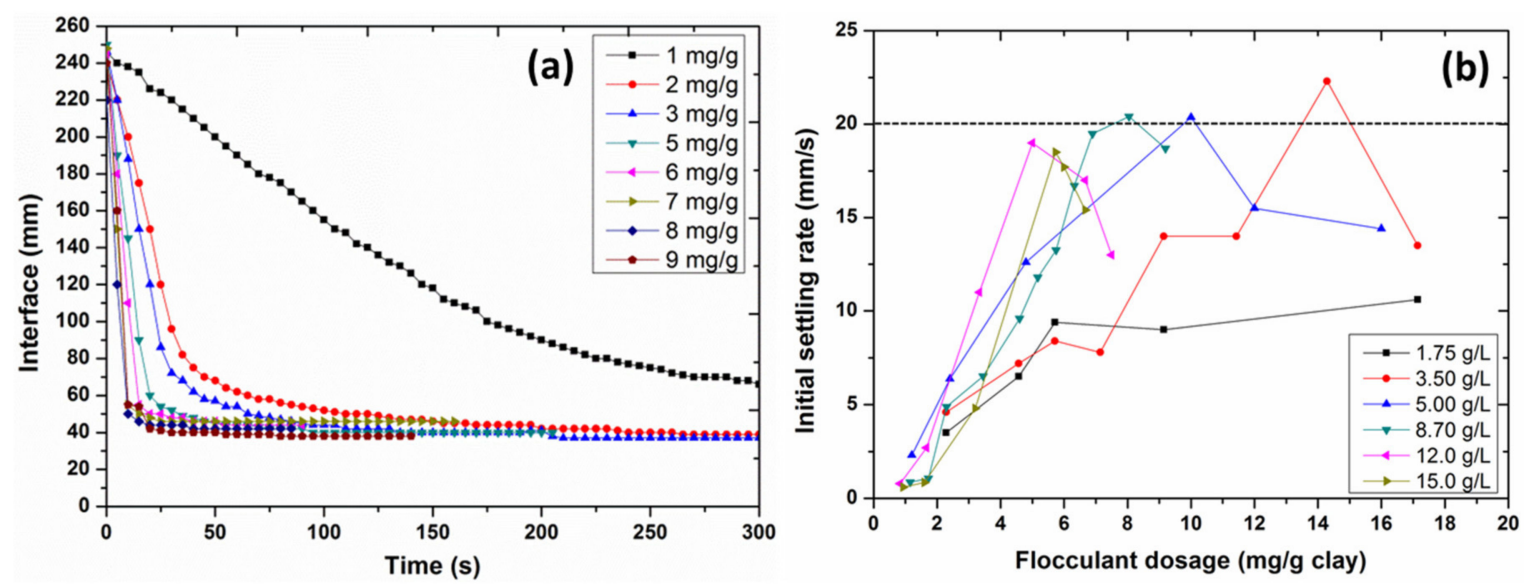

Figure 10. (a) Clay-water interface as a function of time for $8.7 \mathrm{~g} / \mathrm{L}$ clay suspensions in the presence of cationic polyelectrolyte for various flocculant to clay ratios $(\mathrm{mg} / \mathrm{g})$ and $(\mathbf{b})$ initial settling rate as a function of flocculant to clay ratio $(\mathrm{mg} / \mathrm{g})$ for different clay suspensions in the presence of cationic polyelectrolyte.

The optimum settling rate was observed to be about $20 \mathrm{~mm} / \mathrm{s}$ (dotted line in the Figure 10b) for all the clay concentrations except for $1.75 \mathrm{~g} / \mathrm{L}$. In that case, the suspension was so dilute that, as stated above, the standard inversion procedure did not last enough to properly induce flocculation and, hence, we could not clearly distinguish the supernatant from the settling bulk. The optimum flocculant dosage showed an increasing trend with decreasing clay concentration. For lower clay concentrations, the interparticle distance became more important and the standard mixing procedure, i.e., column inversion was not appropriate for optimal mixing. The insufficient mixing was, therefore, compensated by using a larger flocculant dose in order to achieve an optimal settling rate, except for the $1.75 \mathrm{~g} / \mathrm{L}$ clay.

\subsection{Electrophoretic Mobility Measurements}

The simplest relation between zeta potential and flocculation is given as: flocculation should be optimal when the zeta potential is lowest in absolute value [20]. According to the DLVO theory, Van der Waals interactions will ensure aggregation of particles by having zeta potential, i.e., electrokinetic charge, close to zero. In case of polymer-coated particles, non-DLVO forces like hydrogen bonding and steric forces play a (major) role, also in environmental conditions [36]. In particular, the extension of polymer layer coated on a clay particle into the solution can happen beyond the shear plane, i.e., where the zeta potential is defined. The zeta potential would then in principle not be representative of the flocculation ability, as it is the extended polymer tail that will aggregate with other clay particles in suspension, i.e., bridging mechanism. The objective of the present electrophoretic mobility, i.e., zeta potential study was to investigate if a link could be found between the electrokinetic surface charge of polymer coated clay particles and the flocculation behavior.

\subsubsection{Anionic Flocculant}

The zeta potential values of anionic flocculated suspensions as a function of flocculant dosage for different clay concentrations are presented in Figure 11a. Coating of clay particles with anionic polyelectrolyte increase, as expected, their negative charge, i.e., absence of zero surface charge. The zeta potential showed a strong dependency on clay concentration only above $0.35 \mathrm{~g} / \mathrm{L}$. Below $0.35 \mathrm{~g} / \mathrm{L}$ of clay, the same (optimum) coverage of clay particles by the polyelectrolyte was achieved. This can be explained by the low concentration of cations present in the solvent and, therefore, the strong electrostatic repulsion 
between clay and polyelectrolyte particles (all negatively charged). Above $0.35 \mathrm{~g} / \mathrm{L}$, the binding of flocculant to the clay particles, for the given experimental time (a few minutes for sample preparation and measurement), decreased as a function of clay concentration.
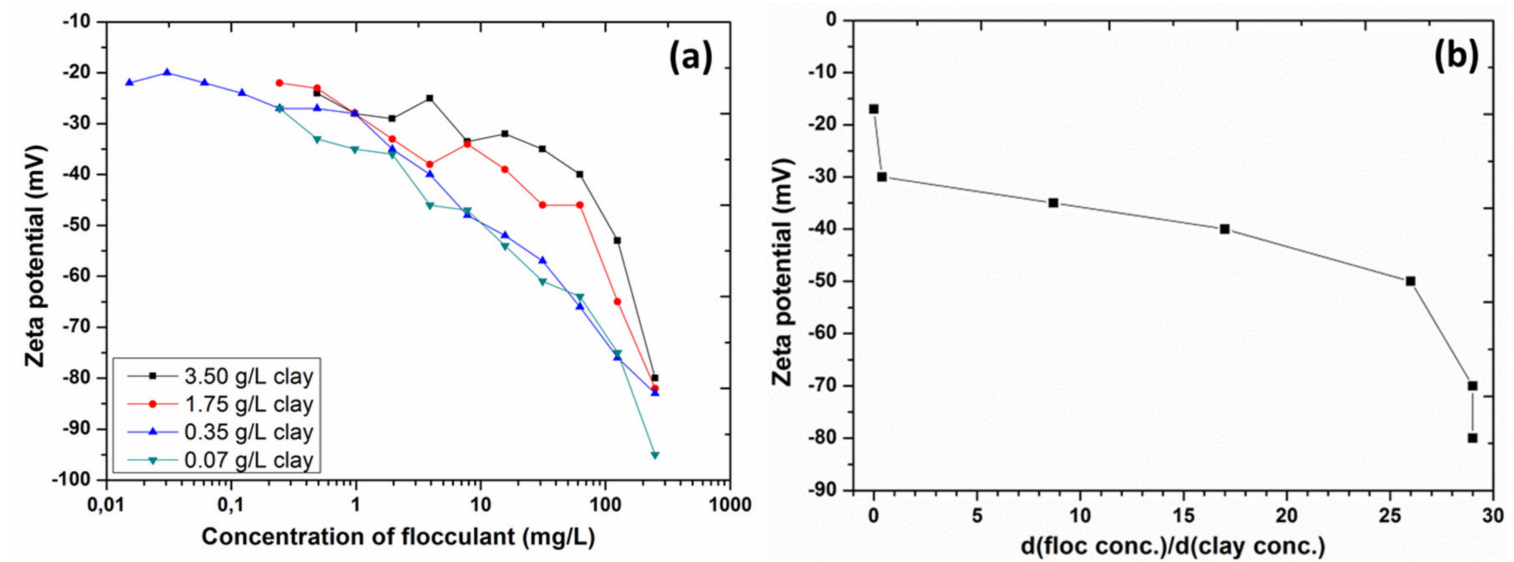

Figure 11. (a) Zeta potential as a function of anionic flocculant concentration for different concentrations of clay and (b) zeta potential as a function of flocculant to clay ratio.

The data of Figure 11a is replotted in Figure $11 \mathrm{~b}$ by estimating an average flocculant to clay ratio from linear interpolation. Three different regions can be identified from Figure 11b: (i) flocculant-clay ratio $<1 \mathrm{mg} / \mathrm{g}$ : represents the optimum binding of flocculant to clay particles, (ii) flocculant-clay ratio $=1-25 \mathrm{mg} / \mathrm{g}$ : shows a linear decrease in electrophoretic mobility, i.e., zeta potential due to less binding of flocculant to clay particles and (iii) flocculant-clay ratio $>25 \mathrm{mg} / \mathrm{g}$ : displays an even stronger decline in zeta potential. This decrease, however, does not correspond to the adsorption/binding of the polyelectrolyte to the clay particles. At high polyelectrolyte concentrations, a significant amount of polyelectrolyte remained in solution and hereby increased the suspension's viscosity that even started to form a gel, as evident by the experiments. This increased viscosity should in theory lead to a decrease in absolute values of the electrophoretic mobility, which is, see Equation (3), inversely proportional to the solvent viscosity. However, this relation between electrophoretic mobility and suspension viscosity does not account for gel electroosmotic flow mobility [37]. The gel mobility has to be subtracted from the measured particle mobility, in order to obtain the particle "true" mobility, i.e., as measured in an immobile solvent. No information about polyelectrolyte binding can, therefore, be obtained from the third region.

\subsubsection{Cationic Flocculant}

The electrophoretic mobility of clay particles flocculated with cationic polyelectrolyte is shown in Figure 12a,b. The binding of the flocculant to the clay particles is clearly limited by the amount of flocculant available for each clay particle. When higher amounts of flocculant were added, the zeta potential for a given clay concentration increased and eventually crossed the zero zeta potential line. The addition of flocculant also resulted in higher viscosity of suspensions, although not enough to make a significant change in the measured mobility, as, in contrast to the anionic flocculant case, most of the polyelectrolyte has then bound to clay. Petzold et al. [38,39] observed a similar increase in zeta potential values as a function of cationic polyelectrolyte concentration for kaolinite flocculation. An optimum flocculant dosage can be defined corresponding to a zero electrophoretic mobility, i.e., zero electrokinetic surface charge. The concentration of the flocculant needed to get a zero zeta potential is almost independent of the clay concentration and found to be in the range 5-6 mg/g clay except for low clay concentrations, i.e., $<0.17 \mathrm{~g} / \mathrm{L}$, which is attributed to an insufficient mixing of the samples at the experimental timescale of the order of a few minutes, see Figure 12c. The measured zeta potential is, therefore, representative for the surface coverage of a clay particle by the polyelectrolyte. 

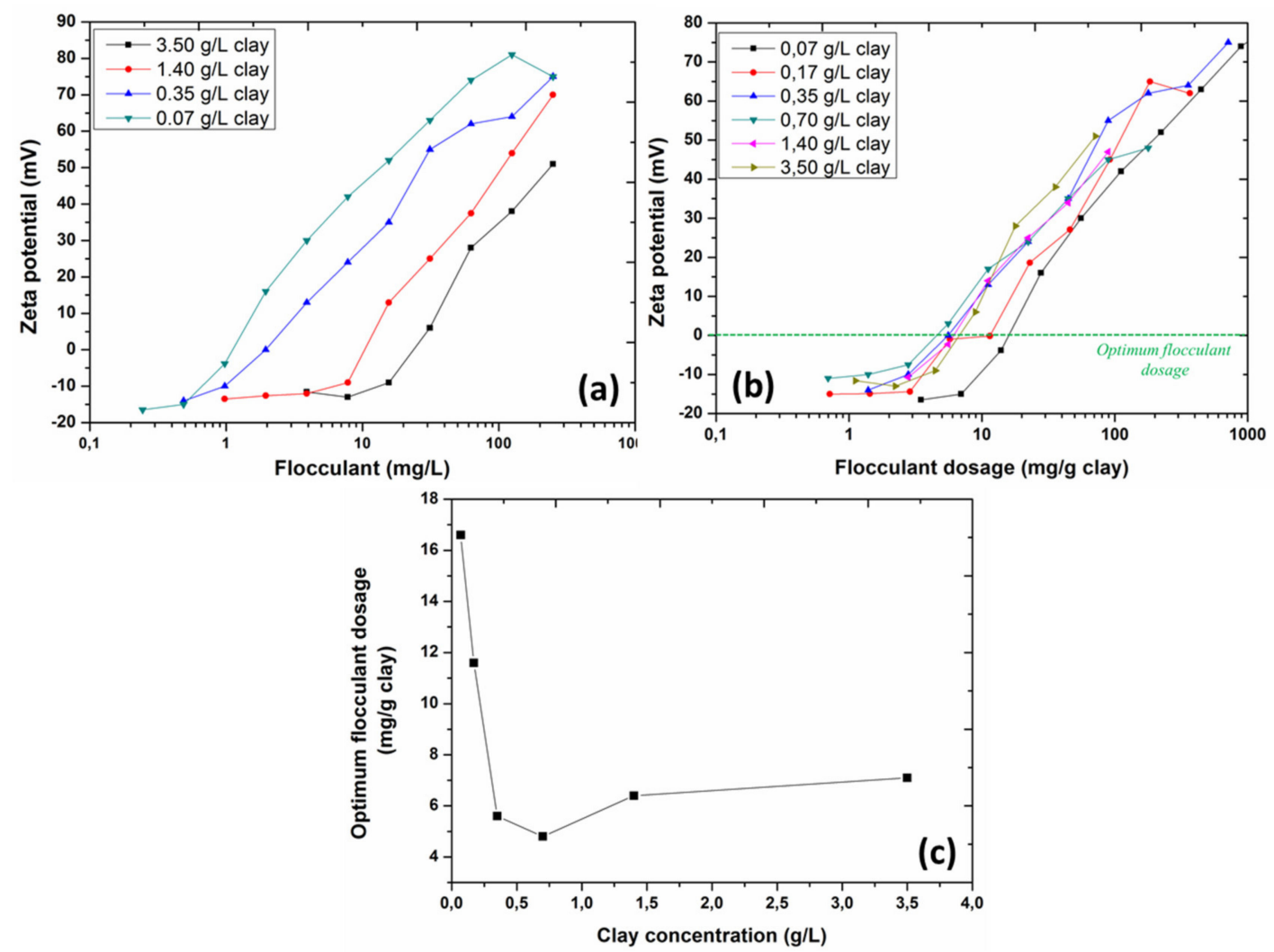

Figure 12. $(\mathbf{a}, \mathbf{b})$ Zeta potential as a function of cationic flocculant concentration $(\mathrm{mg} / \mathrm{L}$ and $\mathrm{mg} / \mathrm{g}$ clay) for different concentrations of clay. The dotted line represents the optimum flocculant dosage required to get the zero value of the zeta potential, (c) optimum flocculant dosage as a function of clay concentration.

\subsection{Rheological Analysis}

The structural recovery in flocculated suspensions, based on anionic and cationic polyelectrolytes, was investigated using structural recovery experiments. Two different concentrations, i.e., 30 and $40 \mathrm{wt} \%$ of clay, were considered for this analysis, in order to have enough interactions between the particles, as indicated by the rheological analysis of pure clay suspensions (see Supplementary information). The flocculant amount was varied to have the flocculant/clay ratio below, at and above the optimal flocculant dosage determined by the other investigated techniques discussed in the sections above.

\subsubsection{Anionic Flocculant}

Figure 13 shows the outcome of structural recovery tests for the suspensions flocculated by anionic polyelectrolyte, in terms of normalized storage modulus as a function of time, after the pre-shearing step. For all the investigated suspensions the structural recovery was either closer to or higher than the initial structural level of the suspensions $\left(G^{\prime} / G_{0}^{\prime} \geq 1\right)$. This result confirmed the shear reversibility of clay-polyanionic flocs, as was found from the SLS measurements. For a low concentration of clay (30 wt \%, Figure 13a), the structural recovery was found to be significantly high in the case of a low flocculant amount. We have shown (see Figure 9 and related discussion) that at a low clay/flocculant amount the experimental time of the standard mixing procedure, i.e., column inversion was not enough for optimal mixing in the settling column experiments. It can, therefore, be hypothesized that the pre-shear step provides this necessary time for a proper mixing of the clay-polyelectrolyte suspension, which eventually resulted in higher structural recovery. This higher recovery of structure may also be linked to the de-mixing of the suspension, i.e., settling of clay particles at such low clay content and 
flocculant amount. The experimental data of storage modulus as a function of time was fitted by using Equation (4) and the values of the fitting parameters are presented in Table 3.
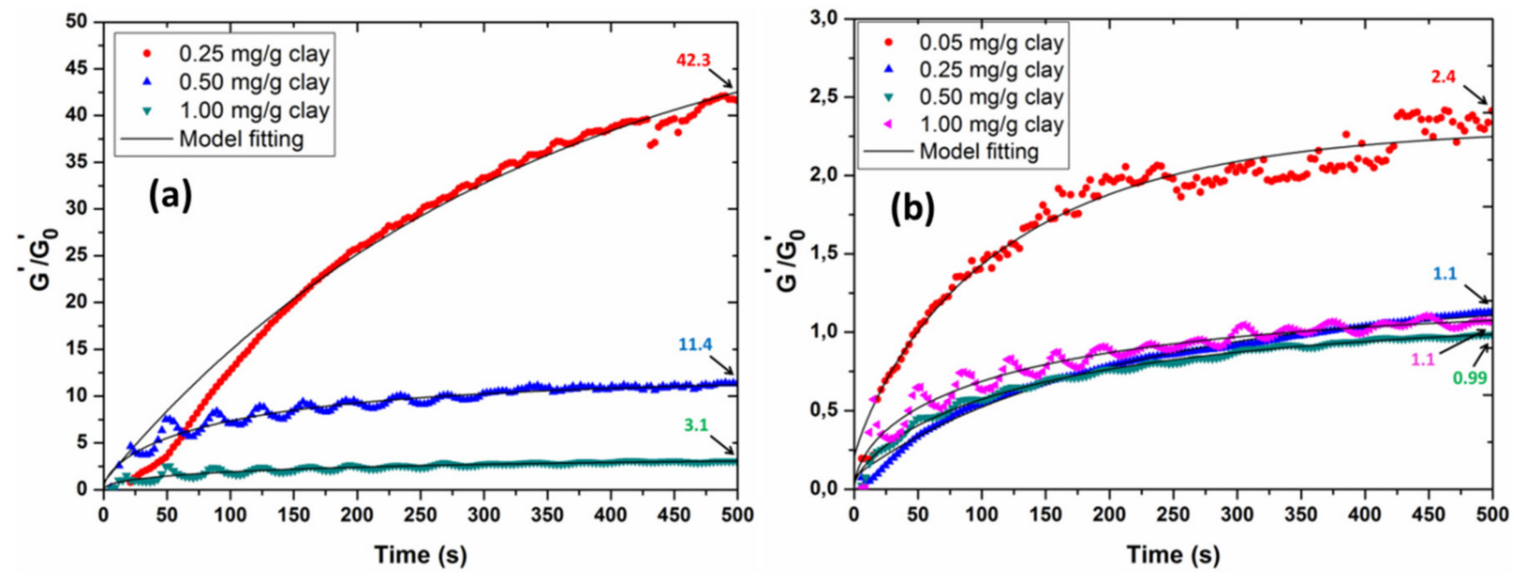

Figure 13. Normalized storage modulus as a function of time, after the pre-shearing step, for different clay suspensions having (a) $30 \mathrm{wt} \%$ and (b) $40 \mathrm{wt} \%$ clay with different amounts of anionic flocculant, solid lines represent the empirical model fitting.

Table 3. The values of the fitting parameters of Equation (4) for anionic polyelectrolyte based clay suspensions.

\begin{tabular}{|c|c|c|c|c|c|c|c|}
\hline Flocculant Dosage & $G_{\infty}^{\prime}(\mathrm{Pa})$ & Standard Error & $t_{r}(\mathrm{~s})$ & Standard Error & $d(-)$ & Standard Error & $G_{\infty}^{\prime} / G_{0}^{\prime}$ \\
\hline \multicolumn{8}{|c|}{$30 \mathrm{wt} \%$ clay } \\
\hline $0.25 \mathrm{mg} / \mathrm{g}$ clay & 421 & 3.1 & 334 & 24 & 0.99 & 0.04 & 55 \\
\hline $0.5 \mathrm{mg} / \mathrm{g}$ clay & 1098 & 21.2 & 115 & 6 & 0.64 & 0.02 & 12 \\
\hline $1 \mathrm{mg} / \mathrm{g}$ clay & 1511 & 33.6 & 230 & 16 & 0.52 & 0.01 & 4 \\
\hline \multicolumn{8}{|c|}{40 wt $\%$ clay } \\
\hline $0.05 \mathrm{mg} / \mathrm{g}$ clay & 266 & 1.7 & 117 & 5 & 0.86 & 0.03 & 2.3 \\
\hline $0.25 \mathrm{mg} / \mathrm{g}$ clay & 378 & 2.8 & 213 & 15 & 0.94 & 0.03 & 1.2 \\
\hline $0.5 \mathrm{mg} / \mathrm{g}$ clay & 888 & 15.8 & 165 & 17 & 0.70 & 0.02 & 1.1 \\
\hline $1 \mathrm{mg} / \mathrm{g}$ clay & 1799 & 36.5 & 136 & 6 & 0.60 & 0.01 & 1.2 \\
\hline
\end{tabular}

\subsubsection{Cationic Flocculant}

The results of the structural recovery of clay suspensions flocculated by cationic polyelectrolyte are shown in Figure 14. For a low concentration of clay (30 wt \%, Figure 14a), the structural recovery was high in the case of a flocculant amount lower than the optimal dosage, which may again be linked to the fact that the pre-shear step provided a better mixing of clay-polyelectrolyte and higher structural recovery. At flocculant amounts equivalent to or higher than the optimal dosage, the structural regrowth was significantly lower, which confirmed the SLS measurements that there is an irreversible breakup of clay-polycationic flocs as a result of the shearing action. For higher clay concentration (40 wt \%, Figure 14b), the irreversible breakup of clay-polyelectrolyte flocs was also evident by a smaller recovery in the storage modulus. Even below the optimal dosage of flocculant $(1 \mathrm{mg} / \mathrm{g})$, the recovery for clay suspensions, having $40 \mathrm{wt} \%$ clay, was quite lower due to the combined effect of irreversible breakage of clay-polyelectrolyte flocs and the existence of two levels of structure, i.e., two-step yielding, as shown in Figure S1a. The oscillations observed in the structural recovery behavior, particularly for higher clay/flocculant concentration, are attributed to the elasticity of the polymer [22,40]. The absence of this oscillating behavior for $30 \mathrm{wt} \%$ clay and $1 \mathrm{mg} / \mathrm{g}$ flocculant dose is linked to the fact that at these concentrations the suspended flocs had minimal interactions. Equation (4) was used to fit the data of storage modulus as a function of time and the values of the fitting parameters for cationic polyelectrolyte based suspensions are presented in Table 4 . 

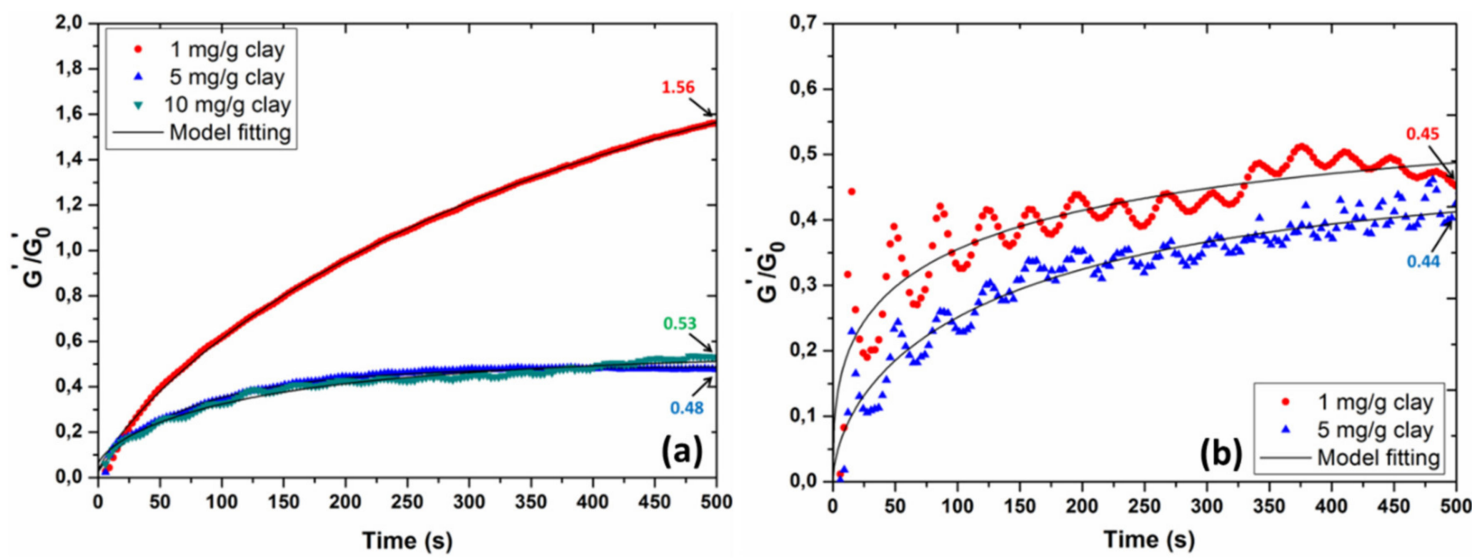

Figure 14. Normalized storage modulus as a function of time, after the pre-shearing step, for different clay suspensions having (a) $30 \mathrm{wt} \%$ and (b) $40 \mathrm{wt} \%$ clay with different amounts of cationic flocculant, solid lines represent the empirical model fitting.

Table 4. The values of the fitting parameters of Equation (4) for cationic polyelectrolyte based clay suspensions.

\begin{tabular}{|c|c|c|c|c|c|c|c|}
\hline Flocculant Dosage & $G_{\infty}^{\prime}(\mathrm{Pa})$ & Standard Error & $t_{r}(\mathrm{~s})$ & Standard Error & $d(-)$ & Standard Error & $G_{\infty}^{\prime} / G_{0}^{\prime}$ \\
\hline \multicolumn{8}{|c|}{$30 \mathrm{wt} \%$ clay } \\
\hline $1 \mathrm{mg} / \mathrm{g}$ clay & 1866 & 38.1 & 448 & 35 & 0.82 & 0.03 & 2.31 \\
\hline $5 \mathrm{mg} / \mathrm{g}$ clay & 14,142 & 654.2 & 79 & 5 & 0.85 & 0.03 & 0.50 \\
\hline $10 \mathrm{mg} / \mathrm{g}$ clay & 27,774 & 1129.4 & 146 & 8 & 0.72 & 0.02 & 0.55 \\
\hline \multicolumn{8}{|c|}{$40 \mathrm{wt} \%$ clay } \\
\hline $1 \mathrm{mg} / \mathrm{g}$ clay & 5914 & 195.4 & 134 & 6 & 0.40 & 0.01 & 0.59 \\
\hline $5 \mathrm{mg} / \mathrm{g}$ clay & 18,306 & 845.3 & 163 & 17 & 0.61 & 0.02 & 0.48 \\
\hline
\end{tabular}

\section{5. (Micro) Structural Observations}

The difference between the flocculation mechanisms for the anionic and the cationic flocculants can be seen in Figure 15a,d, respectively. The flocculated samples were stirred in a $1 \mathrm{~L}$ jar at a shear rate of $25 \mathrm{~s}^{-1}$ and the picture of the jars was taken $10 \mathrm{~min}$ after the stirring was started. Cationic flocculant acts through charge neutralization while anionic flocculant acts through the bridging mechanism. Since the amount of cations present in the demi-water was insufficient for optimal flocculation, the water remained turbid (Figure 15a) and the overall negative charge of the anionic flocs prevented the reconformation of the flocs, as it was observed for the cationic flocs (Figure 15d).

(a)

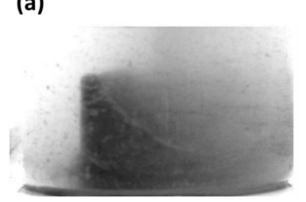

(d)

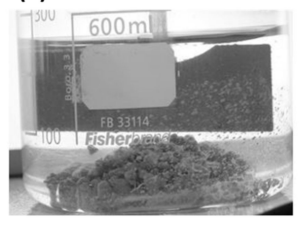

(b)

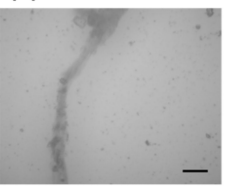

(e)

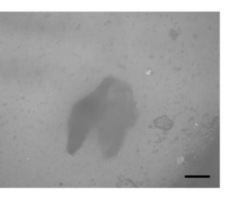

(c)

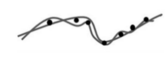

(f)

Figure 15. Images of the jars taken after $10 \mathrm{~min}$ of stirring at $25 \mathrm{~s}^{-1}$ for (a) anionic polyelectrolyte and (d) cationic polyelectrolyte based suspensions. Micrographs of (b) anionic floc and (e) cationic floc. Scale bar represents $70 \mu \mathrm{m}$. Pictorial representation of (c) anionic floc and (f) cationic floc based on the micrographs. All experiments are done in demi-water. 
In order to examine the shape of the clay-polyelectrolyte flocs created with either anionic or cationic flocculants, a parallel plate microscopic system reported in detail elsewhere [41] was used. The flocculated sample was placed on the bottom plate of the device and a gap of $100 \mu \mathrm{m}$ was set between both plates. The shearing of samples was performed in the oscillatory mode at $1 \mathrm{~Hz}$ with the amplitude of $0.4 \mathrm{~mm}$ of the bottom plate. The micrographs of the flocs are presented in Figure 15b,e, respectively. It can be seen from the micrographs that the anionic flocculant formed thin and compact flocs (Figure 15c) while the cationic polyeletrolyte created spherical and open flocs (Figure 15f).

\subsection{Discussion}

\subsubsection{Anionic Flocculant}

From the results presented in the previous sections for the anionic polyelectrolyte, we found that time is an important variable in the study of flocculation by anionic polyelectrolyte, as compared to the cationic one. Small experimental times $(<200 \mathrm{~s})$ for both SLS measurements and electrophoretic mobility (EM) measurements indicated a fast aggregation of the anionic polyelectrolyte to the clay. In both cases, it was observed that the optimal flocculant to clay dosage (corresponding to the initial fast increase in floc size for SLS measurements and a polyelectrolyte adsorption independent of clay concentration for EM measurements) was below $1 \mathrm{mg} / \mathrm{g}$ clay. The flocculation process nonetheless continued for hours and shear-dependent equilibrium sizes were obtained by SLS. From settling column measurements, it was apparent that the flocculation dynamics was time-dependent, as demonstrated by the presence of a second settling rate for large doses of flocculant (see Figure 9). The reason for this long flocculation time is coupled to the fact that flocs were limited in growth during mixing and, hence, were observed to grow further at the onset of the settling. This was also confirmed by rheological analysis, where it was shown that a higher structural recovery was found after a pre-shearing step as compared to the structure before pre-shearing. It is hypothesized that a better (longer) flocculant/clay mixing occurs during pre-shearing. The exact relative roles of cationic bridging and hydrogen bonding during the whole flocculation process cannot be determined, but since cationic bridging is related to an attractive Coulombic force, one may suppose that cationic bridging played an important role at shorter experimental times.

For the SLS and EM measurements, demi-water was used to prepare the samples whereas for settling column experiments, tap water was used to prepare the stock suspension before dilution, which resulted in the presence of a higher amount of cations. When pure demi-water was used to study the settling behavior, the interfaces were very difficult to recognize, as the suspensions remained highly turbid. The main force in the system was then electrostatic repulsion, which in particular led to the extended polymeric structures observed by eye and video microscopy. Using tap water led to a new optimal flocculant to clay ratio of $2.28 \mathrm{mg} / \mathrm{g}$ and the settling rates were fairly independent of clay concentrations below $7 \mathrm{~g} / \mathrm{L}$ clay, indicating that flocculation was not limited by the amount of cations present, as was the case during the experiments with demi-water. It remains to be investigated if changing the electrolyte composition, i.e., from fresh to sea water composition, would lead to differences in flocculation. The influence of the type of cations on the flocculation behavior was investigated by other authors, who found that divalent cations particularly promote flocculation [4,42].

Contrary to flocculation by the cationic polyelectrolyte, the floc growth at the onset of settling and the shear independent floc sizes studied by SLS indicated that the links between the anionic polyelectrolyte and clay were weak enough to have reversible binding with the clay at different shearing levels without damage. This was confirmed by rheological measurements, as for all the investigated suspensions the structural recovery was either closer to or higher than the initial structural level $\left(G^{\prime} / G_{0}^{\prime} \geq 1\right)$. 


\subsubsection{Cationic Flocculant}

The interactions between the polyelectrolyte and clay were driven by electrostatic attraction in the case of polycations/clay mixtures. This resulted in extremely fast aggregation mechanisms and the timescale for the standard column inversion procedure (30 s) was usually enough to have the sample flocculated. This is confirmed by SLS measurements, where more dilute samples were used, but even then less than $100 \mathrm{~s}$ were required to achieve the largest observed $\mathrm{D}_{50}$. For the highest clay concentrations (12 and $15 \mathrm{~g} / \mathrm{L}$ ) the optimum flocculant to clay ratio was close to $5 \mathrm{mg} / \mathrm{g}$, as observed by settling column experiments. For clay concentrations ranging from 1.75 to $8.7 \mathrm{~g} / \mathrm{L}$, the mixing using the standard column inversion procedure was not optimum, which implies that higher flocculant doses were required to achieve an optimum initial settling rate. The optimum flocculant dose, in that case, for fastest settling did not correspond to the maximum clarity of the supernatant, as is usually assumed. At optimal mixing, however, optimal settling and optimal supernatant clarity were found for the same flocculant dosage for a given clay concentration. The link between zero electrophoretic mobility and supernatant clarity maximum has been reported in the literature [43]. We found from EM measurements that the optimum flocculant dose was close to $5 \mathrm{mg} / \mathrm{g}$ for $0.35-3.50 \mathrm{~g} / \mathrm{L}$ clay, which is the same dose as the one found by settling column experiments, at optimum mixing. For lower clay concentrations $(0.07 \mathrm{~g} / \mathrm{L}$ and $0.17 \mathrm{~g} / \mathrm{L})$ we found, by EM measurements, in line with settling column experiments, that larger flocculant doses were necessary. Even though the supernatant clarity was not maximum, the best supernatant clarity, nonetheless, corresponded to the expected optimum flocculant to clay ratio, in case of poorly mixed suspensions $(1.75-8.7 \mathrm{~g} / \mathrm{L})$.

The equilibrium floc size was found to strongly depend on shear history. This was confirmed by the observations made in the jar and by video microscopy, where, under the action of shear the flocs were seen to coil and form dense spherical aggregates (Figure 15). This was also confirmed by rheological measurements, as for all but one experiment, the structural recovery was lower than the initial structural level $\left(G^{\prime} / G_{0}^{\prime}<1\right)$. Only for the lowest flocculant dose with lowest clay concentration, $G^{\prime} / G_{0}^{\prime}=1.56$ was found, implying that the structural recovery was complete.

\section{Conclusions}

Clayey suspensions, majorly composed of quartz microparticles, in the presence of anionic and cationic polyelectrolytes, at very low salinity, were investigated. The clay concentration was varied from 0.07 to $15 \mathrm{~g} / \mathrm{L}$ for static light scattering experiments, from 1.75 to $15 \mathrm{~g} / \mathrm{L}$ for settling column experiments, from 0.07 to $3.5 \mathrm{~g} / \mathrm{L}$ for electrophoretic mobility analysis and from 110 to $1000 \mathrm{~g} / \mathrm{L}$ for rheological investigation. The suspensions were studied at extremely low shear by the column inversion method and higher shear (even though the lowest possible with the method) by static light scattering. The optimum flocculant to clay ratio was defined as the ratio that gives the fastest initial floc growth by static light scattering and the fastest initial settling rate during setting column experiments. It was, in particular, found that all the experimental techniques agreed well with each other, and despite the wide range of clay concentration and shearing level, general conclusions could be drawn. Of particular importance for further research on in-situ flocculation with polymeric agents, the following findings were found:

- The presence of cations in the water was determinant for the flocculation efficiency and flocculation dynamics of clay in the presence of anionic polyelectrolyte. The shape of the flocs was found to be very elongated in cation-poor water. It remains to be investigated how this conformation would change in saline water, and how the flocculation dynamics would be affected. Preliminary studies have shown that the order in which the polyanionic flocculant, clay and electrolyte are mixed has a large influence on the obtained flocs. This is of particular importance for estuarine conditions, where changes from fresh to saline water take place. Even though it is not discussed in the present article, the fact that particles are elongated also lead to problems in the analysis of the light scattering data, as most software are made for the analysis of spherical shaped objects. It is known 
that the interpretation of in-situ light scattering data is in particular affected by the presence of elongated particles.

- The size of flocs obtained by the anionic flocculant is reversible upon shear, implying that these are independent of shear history. The main reason for this reversibility is that the clay and polyelectrolyte attach through cation bridging, which is a weak interaction. It remains to be seen, in the case of natural polyanions, like humic substances of low to moderate molecular weight (which can be surface active), if other forces for instance steric forces could play an additional role and lead to different aggregate structures and flocs of different sizes and strength.

- The large flocs obtained by the cationic flocculant were formed by a strong electrostatic attraction and their shape and size was extremely shear-dependent, making them history dependent: their properties depend not only on the shear level but also on the time that a given shear is applied. The fact that flocs can reconform under shear, i.e., become denser without loss of clay and polymer mass, has consequences in terms of modelling, as aggregation models are based on the fact that particles can change their size upon aggregation or break-up but not because of a change in volume without a loss of mass.

Supplementary Materials: The following are available online at http://www.mdpi.com/2075-163X/10/11/999/s1, Rheological analysis (i.e., by performing stress ramp-up, frequency sweep and structural recovery tests) and settling behavior of clay suspensions without flocculant as a function of clay concentration. "References [44-62] are cited in the supplementary materials".

Author Contributions: Conceptualization, M.I. and Z.S.; Methodology, M.I. and Z.S.; Formal Analysis, A.S. and M.I.; Investigation, A.S., M.I. and Z.S.; Writing-Original Draft Preparation, M.I. and Z.S.; Writing-Review \& Editing, A.S., L.v.P. and C.C.; Supervision, L.v.P. and C.C.; Funding Acquisition, L.v.P. and C.C. All authors have read and agreed to the published version of the manuscript.

Funding: Part of this study was performed as part of the CEAMaS (Civil Engineering Applications of Marine Sediments) project, which was supported by the European Regional Development Funding through INTERREG IV B and the Dutch Technology Foundation STW, which is part of the Netherlands Organisation for Scientific Research (NWO), and which is partly funded by the Ministry of Economic Affairs. The APC was funded by TU Delft, the Netherlands.

Acknowledgments: The authors would like to thank MSc. student Michiel Cornelis (M.C.) Ooms for performing the preliminary experiments, which ultimately led to the present article. Deltares (Rotterdamsweg) is also gratefully acknowledged for facilitating the measurements.

Conflicts of Interest: The authors declare no conflict of interest.

\section{References}

1. Liss, S.N.; Milligan, T.G.; Droppo, I.G.; Leppard, G.G. Methods for analyzing floc properties. In Flocculation in Natural and Engineered Environmental Systems; CRC Press: Boca Raton, FL, USA, 2005.

2. Manning, A.; Baugh, J.; Soulsby, R.; Spearman, J.; Whitehouse, R. Cohesive sediment flocculation and the application to settling flux modelling. In Sediment Transport; Ginsberg, S.S., Ed.; IntechOpen: Rijeka, Croatia, 2011; pp. 91-116.

3. Bergaya, F.; Lagaly, G. Handbook of Clay Science; Newnes: Amsterdam, The Netherland, 2013; Volume 5.

4. Lee, B.J.; Schlautman, M.A.; Toorman, E.; Fettweis, M. Competition between kaolinite flocculation and stabilization in divalent cation solutions dosed with anionic polyacrylamides. Water Res. 2012, 46, 5696-5706. [CrossRef]

5. Mietta, F.; Chassagne, C.; Winterwerp, J.C. Shear-induced flocculation of a suspension of kaolinite as function of $\mathrm{pH}$ and salt concentration. J. Colloid Interface Sci. 2009, 336, 134-141. [CrossRef] [PubMed]

6. Tan, X.-1.; Zhang, G.-p.; Yin, H.; Reed, A.H.; Furukawa, Y. Characterization of particle size and settling velocity of cohesive sediments affected by a neutral exopolymer. Int. J. Sediment Res. 2012, 27, 473-485. [CrossRef]

7. Bolto, B.; Gregory, J. Organic polyelectrolytes in water treatment. Water Res. 2007, 41, $2301-2324$. [CrossRef] [PubMed]

8. Concha Arcil, F. Settling Velocities of Particulate Systems. Kona Powder Part. J. 2009, 27, 18-37. [CrossRef]

9. Mierczynska-Vasilev, A.; Kor, M.; Addai-Mensah, J.; Beattie, D.A. The influence of polymer chemistry on adsorption and flocculation of talc suspensions. Chem. Eng. J. 2013, 220, 375-382. [CrossRef]

10. Goodwin, J. Colloids and Interfaces with Surfactants and Polymers; John Wiley \& Sons: West Sussex, UK, 2009. 
11. Barany, S.; Meszaros, R.; Kozakova, I.; Skvarla, I. Kinetics and mechanism of flocculation of bentonite and kaolin suspensions with polyelectrolytes and the strength of floccs. Colloid J. 2009, 71, 285-292. [CrossRef]

12. Barany, S.; Kozakova, I.; Marcinova, L.; Skvarla, J. Electrokinetic potential of bentonite and kaolin particles in the presence of polymer mixtures. Colloid J. 2010, 72, 595-601. [CrossRef]

13. Bárány, S.; Meszaros, R.; Marcinova, L.; Skvarla, J. Effect of polyelectrolyte mixtures on the electrokinetic potential and kinetics of flocculation of clay mineral particles. Colloids Surf. A Physicochem. Eng. Asp. 2011, 383, 48-55. [CrossRef]

14. Stewart, C.; Thompson, J.A.J. Vertical Distribution of Butyltin Residues in Sediments of British Columbia Harbours. Environ. Technol. 1997, 18, 1195-1202. [CrossRef]

15. McLaughlin, R.A.; Bartholomew, N. Soil factors influencing suspended sediment flocculation by polyacrylamide. Soil Sci. Soc. Am. J. 2007, 71, 537-544.

16. Sojka, R.E.; Bjorneberg, D.L.; Entry, J.A.; Lentz, R.D.; Orts, W.J. Polyacrylamide in Agriculture and Environmental Land Management. In Advances in Agronomy; Sparks, D.L., Ed.; Academic Press: Cambridge, MA, USA, 2007; Volume 92, pp. 75-162.

17. Mietta, F.; Maggi, F.; Winterwerp, J.C. Chapter 19 Sensitivity to breakup functions of a population balance equation for cohesive sediments. In Proceedings in Marine Science; Kusuda, T., Yamanishi, H., Spearman, J., Gailani, J.Z., Eds.; Elsevier: Amsterdam, The Netherlands, 2008; Volume 9, pp. 275-286.

18. Malvern. Available online: www.malvern.com (accessed on 10 April 2020).

19. Bouyer, D.; Coufort, C.; Liné, A.; Do-Quang, Z. Experimental analysis of floc size distributions in a 1-L jar under different hydrodynamics and physicochemical conditions. J. Colloid Interface Sci. 2005, 292, 413-428. [CrossRef] [PubMed]

20. Hunter, R.J. Zeta Potential in Colloid Science: Principles and Applications; Academic Press: London, UK, 1981; Volume 2.

21. Chassagne, C.; Ibanez, M. Hydrodynamic size and electrophoretic mobility of latex nanospheres in monovalent and divalent electrolytes. Colloids Surf. A Physicochem. Eng. Asp. 2014, 440, 208-216. [CrossRef]

22. Shakeel, A.; Kirichek, A.; Chassagne, C. Effect of pre-shearing on the steady and dynamic rheological properties of mud sediments. Mar. Pet. Geol. 2020, 116, 104338. [CrossRef]

23. Gregory, J. Rates of flocculation of latex particles by cationic polymers. J. Colloid Interface Sci. 1973, 42, 448-456. [CrossRef]

24. Mpofu, P.; Addai-Mensah, J.; Ralston, J. Investigation of the effect of polymer structure type on flocculation, rheology and dewatering behaviour of kaolinite dispersions. Int. J. Miner. Process. 2003, 71, 247-268. [CrossRef]

25. Mpofu, P.; Addai-Mensah, J.; Ralston, J. Flocculation and dewatering behaviour of smectite dispersions: Effect of polymer structure type. Miner. Eng. 2004, 17, 411-423. [CrossRef]

26. Sworska, A.; Laskowski, J.S.; Cymerman, G. Flocculation of the Syncrude fine tailings: Part I. Effect of pH, polymer dosage and $\mathrm{Mg}^{2+}$ and $\mathrm{Ca}^{2+}$ cations. Int. J. Miner. Process. 2000, 60, 143-152. [CrossRef]

27. Sworska, A.; Laskowski, J.S.; Cymerman, G. Flocculation of the Syncrude fine tailings: Part II. Effect of hydrodynamic conditions. Int. J. Miner. Process. 2000, 60, 153-161. [CrossRef]

28. Bubakova, P.; Pivokonsky, M.; Filip, P. Effect of shear rate on aggregate size and structure in the process of aggregation and at steady state. Powder Technol. 2013, 235, 540-549. [CrossRef]

29. Mietta, F. Evolution of the Floc Size Distribution of Cohesive Sediments. Ph.D. Thesis, Delft University of Technology, Delft, The Netherlands, 2010.

30. Yoon, S.-Y.; Deng, Y. Flocculation and reflocculation of clay suspension by different polymer systems under turbulent conditions. J. Colloid Interface Sci. 2004, 278, 139-145. [CrossRef] [PubMed]

31. Zhao, Y.Q. Settling behaviour of polymer flocculated water-treatment sludge I: Analyses of settling curves. Sep. Purif. Technol. 2004, 35, 71-80. [CrossRef]

32. Chen, G.W.; Chang, I.L.; Hung, W.T.; Lee, D.J. Regimes for zone settling of waste activated sludges. Water Res. 1996, 30, 1844-1850. [CrossRef]

33. Fargues, C.; Turchiuli, C. Structural Characterization of Flocs in Relation to Their Settling Performances. Chem. Eng. Res. Des. 2003, 81, 1171-1178. [CrossRef]

34. Owen, A.T.; Fawell, P.D.; Swift, J.D.; Labbett, D.M.; Benn, F.A.; Farrow, J.B. Using turbulent pipe flow to study the factors affecting polymer-bridging flocculation of mineral systems. Int. J. Miner. Process. 2008, 87, 90-99. [CrossRef] 
35. Wen, H.J.; Liu, C.I.; Lee, D.J. Size and density of flocculated sludge flocs. J. Environ. Sci. Health. Part A Environ. Sci. Eng. Toxicol. 1997, 32, 1125-1137. [CrossRef]

36. Grasso, D.; Subramaniam, K.; Butkus, M.; Strevett, K.; Bergendahl, J. A review of non-DLVO interactions in environmental colloidal systems. Rev. Environ. Sci. Biotechnol. 2002, 1, 17-38. [CrossRef]

37. Li, F.; Allison, S.A.; Hill, R.J. Nanoparticle gel electrophoresis: Soft spheres in polyelectrolyte hydrogels under the Debye-Hückel approximation. J. Colloid Interface Sci. 2014, 423, 129-142. [CrossRef]

38. Petzold, G.; Nebel, A.; Buchhammer, H.-M.; Lunkwitz, K. Preparation and characterization of different polyelectrolyte complexes and their application as flocculants. Colloid Polym. Sci. 1998, 276, 125-130. [CrossRef]

39. Petzold, G.; Mende, M.; Lunkwitz, K.; Schwarz, S.; Buchhammer, H.M. Higher efficiency in the flocculation of clay suspensions by using combinations of oppositely charged polyelectrolytes. Colloids Surf. A Physicochem. Eng. Asp. 2003, 218, 47-57. [CrossRef]

40. Goudoulas, T.B.; Germann, N. Viscoelastic properties of polyacrylamide solutions from creep ringing data. J. Rheol. 2016, 60, 491-502. [CrossRef]

41. Shakeel, A.; van Kan, P.J.M.; Chassagne, C. Design of a parallel plate shearing device for visualization of concentrated suspensions. Measurement 2019, 145, 391-399. [CrossRef]

42. Borkovec, M.; Behrens, S.H.; Semmler, M. Observation of the Mobility Maximum Predicted by the Standard Electrokinetic Model for Highly Charged Amidine Latex Particles. Langmuir 2000, 16, 5209-5212. [CrossRef]

43. Narkis, N.; Ghattas, B.; Rebhun, M.; Rubin, A. Mechanism of flocculation with aluminium salts in combination with polymeric flocculants as flocculant aids. Water Supply 1991, 9, 37-44.

44. Barnes, H.A. A review of the slip (wall depletion) of polymer solutions, emulsions and particle suspensions in viscometers: Its cause, character, and cure. J. Nonnewton Fluid Mech. 1995, 56, 221-251. [CrossRef]

45. Chassagne, C. Understanding the natural consolidation of slurries using colloid science. In Proceedings of the European Conference on Soil Mechanics and Geotechnical Engineering, Reykjavik, Iceland, 1-6 September 2019.

46. Dhont, J.K. An Introduction to Dynamics of Colloids; Elsevier: Amsterdam, The Netherlands, 1996.

47. Faas, R.W.; Wartel, S.I. Rheological properties of sediment suspensions from Eckernförde and Kieler Förde Bays, western Baltic Sea. Int. J. Sediment Res. 2006, 21, 24-41.

48. Huang, Z.; Aode, H. A laboratory study of rheological properties of mudflows in Hangzhou Bay, China. Int. J. Sediment Res. 2009, 24, 410-424. [CrossRef]

49. Kanai, H.; Navarrete, R.C.; Macosko, C.W.; Scriven, L.E. Fragile networks and rheology of concentrated suspensions. Rheol. Acta 1992, 31, 333-344. [CrossRef]

50. Koumakis, N.; Petekidis, G. Two step yielding in attractive colloids: Transition from gels to attractive glasses. Soft Matter 2011, 7, 2456-2470. [CrossRef]

51. Kramb, R.C.; Zukoski, C.F. Yielding in dense suspensions: Cage, bond, and rotational confinements. J. Phys. Condens. Matter 2010, 23, 035102. [CrossRef]

52. Maranzano, B.J.; Wagner, N.J. The effects of interparticle interactions and particle size on reversible shear thickening: Hard-sphere colloidal dispersions. J. Rheol. 2001, 45, 1205-1222. [CrossRef]

53. Mewis, J.; Wagner, N.J. Colloidal Suspension Rheology; Cambridge University Press: Cambridge, UK, 2012.

54. Mobuchon, C.; Carreau, P.J.; Heuzey, M.-C. Structural analysis of non-aqueous layered silicate suspensions subjected to shear flow. J. Rheol. 2009, 53, 1025-1048. [CrossRef]

55. O'Brien, J.S.; Julien, P.Y. Laboratory Analysis of Mudflow Properties. J. Hydraul. Eng. 1988, 114, 877-887. [CrossRef]

56. Richardson, J.F.; Zaki, W.N. The sedimentation of a suspension of uniform spheres under conditions of viscous flow. Chem. Eng. Sci. 1954, 3, 65-73. [CrossRef]

57. Shakeel, A.; Kirichek, A.; Chassagne, C. Is density enough to predict the rheology of natural sediments? Geo-Marine Letters 2019, 39, 427-434. [CrossRef]

58. Shakeel, A.; Kirichek, A.; Chassagne, C. Rheological analysis of mud from Port of Hamburg, Germany. J. Soils Sediments. 2020, 20, 2553-2562. [CrossRef]

59. Soltanpour, M.; Samsami, F. A comparative study on the rheology and wave dissipation of kaolinite and natural Hendijan Coast mud, the Persian Gulf. Ocean Dyn. 2011, 61, 295-309. [CrossRef]

60. Van Kessel, T.; Blom, C. Rheology of cohesive sediments: Comparison between a natural and an artificial mud. J. Hydraul. Res. 1998, 36, 591-602. [CrossRef] 
61. Xu, J.; Huhe, A. Rheological study of mudflows at Lianyungang in China. Int. J. Sediment Res. 2016, 31, 71-78. [CrossRef]

62. Zhu, L.; Sun, N.; Papadopoulos, K.; Kee, D.D. A slotted plate device for measuring static yield stress. J. Rheol. 2001, 45, 1105-1122. [CrossRef]

Publisher's Note: MDPI stays neutral with regard to jurisdictional claims in published maps and institutional affiliations.

(C) 2020 by the authors. Licensee MDPI, Basel, Switzerland. This article is an open access article distributed under the terms and conditions of the Creative Commons Attribution (CC BY) license (http://creativecommons.org/licenses/by/4.0/). 